\title{
Relationship between social anxiety and perceived trustworthiness
}

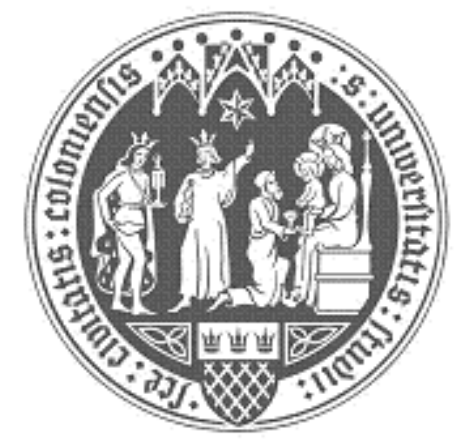

Inaugural-Dissertation

zur

Erlangung des Doktorgrades

der Humanwissenschaftlichen Fakultät

der Universität zu Köln

vorgelegt von

Ruth Cooper

aus Münster

Köln 2012 
1. Berichterstatter: Prof. Dr. Alexander L. Gerlach (Köln)

2. Berichterstatter: Prof. Dr. Jutta Stahl (Köln)

Tag der mündlichen Prüfung: 10.04.2013 


\section{Table of Contents}

\begin{tabular}{|c|c|}
\hline & Abstract.. \\
\hline 1 & Introduction....... \\
\hline 2 & Social Anxiety Disorder....................... \\
\hline 2.1 & 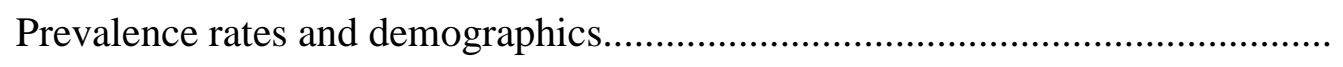 \\
\hline 2.2 & 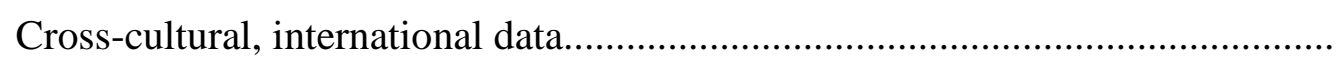 \\
\hline 2.3 & Comorbidity........................................ \\
\hline 2.4 & 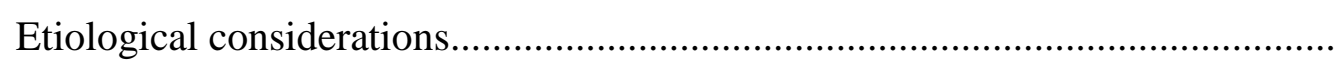 \\
\hline 2.5 & 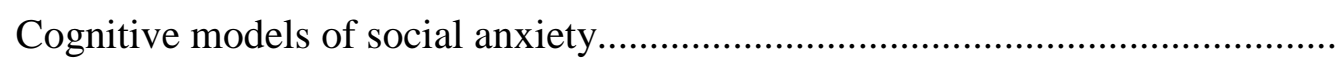 \\
\hline 2.6 & Cognitive biases in face processing \\
\hline
\end{tabular}

$3 \quad$ Interpretation of facial expressions in social anxiety ................................... p. 19

3.1 Biased interpretation of negative facial expressions..................................... p. p. 20

3.2 Biased interpretation of neutral facial expressions....................................... p. 22

3.3 Biased interpretation of positive facial expressions....................................... p. 24

3.4 Discussion and integration of results to date.............................................. p. 25

$4 \quad$ Testing hypotheses or testing the data? ................................................ p. 28

4.1 The principle of falsification..................................................................... p. p. 28

4.2 Null hypothesis significance testing ........................................................ p. 32

4.3 Bayesian evaluation of informative hypotheses................................................. p. 39

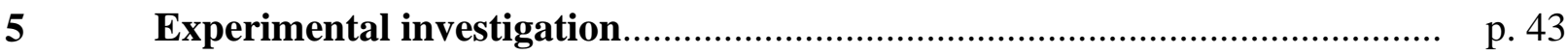

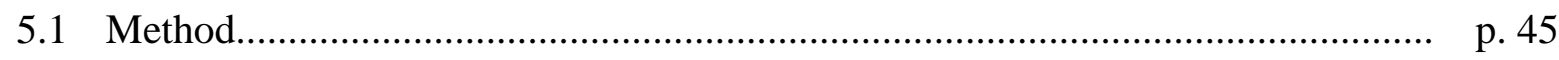

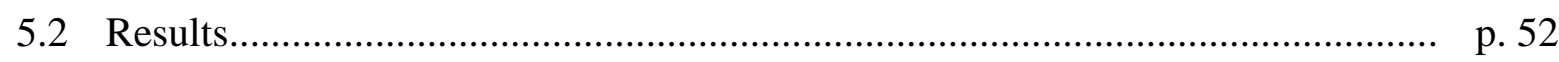

5.3 Discussion................................................................................... p. 55

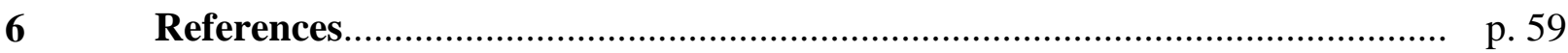

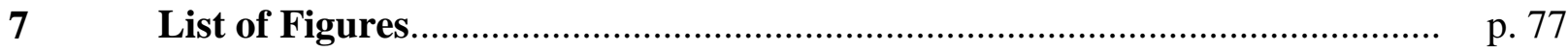

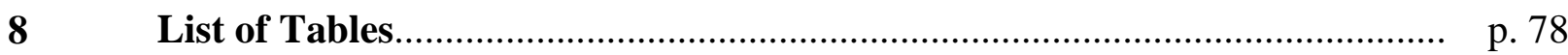

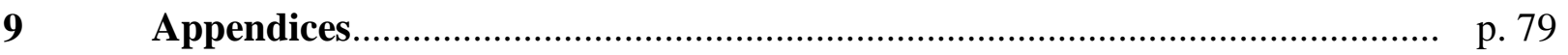




\begin{abstract}
Background and Objectives: Given that the correct interpretation of emotional facial expressions is an essential social skill, it has been repeatedly tested if socially anxious persons show an interpretational bias for emotional faces. Studies examining interpretational biases have revealed inconsistent findings, resulting in four possible bias patterns. However, the assessment may have been hampered by employing more general ratings that arguably are less able to reflect processing of social information.

We examined the relationship between social anxiety and face ratings for perceived trustworthiness given that trustworthiness is an inherently socially relevant construct. Improving on earlier analytical strategies, we directly evaluated the four bias patterns using a Bayesian approach to test informative hypotheses.

Method: Ninety-eight undergraduates rated 198 face stimuli on perceived trustworthiness and intelligence, the latter serving as a control condition. Subsequently, participants completed a set of questionnaires.

Results: It was three times more likely that social anxiety does not influence trustworthiness judgments than assuming any kind of negative interpretation bias in social anxiety. Also, this independence model reached the best fit for perceived intelligence, indicating that social anxiety does not have a prominent influence on intelligence ratings. Limitations: Since we did not assess the participant's diagnostic status, we cannot generalize our findings to clinical levels of social anxiety.

Conclusions: We conclude that the deviant interpretation of facial characteristics is not a relevant aspect in social anxiety.
\end{abstract}




\section{Introduction}

Social anxiety disorder is an impairing mental condition that is above all characterized by the fear of being evaluated negatively (D. M. Clark \& Wells, 1995). Social fears are quite common in the general population and can range from simple and clear-cut situational performance fears, such as being afraid to publicly speak in front of a larger audience, to clinically relevant anxiety and avoidance behavior regarding a huge variety of basically all types of social situations (Ruscio et al., 2008). A clear sign of disapproval or rejection in all sorts of social situations is a negative or threatening facial expression (Öhman, 1986). Consequently, negative facial expressions have been hypothesized to function as anxiety provoking cues for persons which are especially concerned about being evaluated in a negative way (Rapee \& Heimberg, 1997). However, the notion of a specific salience towards negative facial expressions can be explained by multiple different and distinct cognitive processing mechanisms. For instance, it can be assumed that socially anxious persons differ in their allocation of visual attention in response to threatening facial expressions. Another possible cause for the presumed sensitivity lies in a different perception of negative facial expressions in the way that socially anxious persons may recognize threatening faces faster, more frequently, or even more accurate as compared to controls. Furthermore, socially anxious persons might interpret the same facial expressions as more negative or threatening relative to persons without social fears. Finally, it can be assumed that socially anxious persons show a memory bias towards negative facial expressions in the way that these might be remembered better or more often. On the other hand, other accounts for social anxiety (Trower \& Gilbert, 1989) claim that social fears may be particularly related to overlooking or ignoring signs for secure interactions, such as positive facial expressions. 
Considering the vast possibilities of how and where biases related to social anxiety emerge in facial processing, the aim of this study is to give an overview of the current state of research of specifically interpretational biases concerning negative, neutral, and positive facial expressions: Does social anxiety lead to a more negative interpretation of negative facial expressions? Or do social fears attenuate positive evaluations of positive expressions? Or is it perhaps neither of the two, and instead social fears go together with an especially negative interpretation of a neutral facial expression? Or can it simply be that there is no interpretational bias of facial expressions in social anxiety?

The experimental part of this thesis will try to answer these four questions by employing a novel analytical approach. The empirical support for each of the questions will be directly compared to find the most likely answer. Thus, in order to shed some light on the inconclusive results to date, this study will investigate the intriguing issue of how social anxiety is related to interpretational biases of facial expressions. 


\section{Social Anxiety Disorder}

Fear and anxiety in the context of social situations have been noted throughout history, but the notion of social anxiety disorder (SAD) as it is known today dates back to 1966 when Marks and Gelder described a psychopathological syndrome characterized by anxiety experienced while performing specific social tasks, and while potentially being scrutinized by others. It wasn’t until 1980, however, when the American Psychiatric Association issued the third edition of the Diagnostic and Statistical Manual of Mental Disorders (DSM-III; American Psychiatric Association), that SAD was officially acknowledged as a diagnostic entity of its own.

The most recent iteration of the DSM (DSM-IV-TR, American Psychiatric Association, 2000) identifies five criteria as essential for a diagnosis of SAD. First, SAD's core diagnostic feature (Criterion A) is a marked or persistent fear of one or more social or performance situations that are characterized by exposure to unfamiliar people and possible scrutiny. This fear may be experienced in settings that involve formal evaluations, such as job interviews, or generalize to situations in which any form of social contact needs to be initiated or maintained. Thus, even mundane situations (e.g., eating in a restaurant, reading and writing in front of others) or social mishaps (e.g., spilling a drink) can create severe concerns for persons with SAD. Some SAD patients' fears are limited to specific settings or situations, such as being afraid of giving a speech in front of a larger audience (i.e., nongeneralized or circumscribed SAD), whereas others fear nearly any situation involving social interaction (i.e., generalized SAD).

The second diagnostic criterion, Criterion B, states that exposure to a feared social situation almost invariably provokes anxiety or even a full-blown panic attack. The 
experience of anxiety may include typical symptoms of sympathetic arousal, such as heart palpitations, sweating, shaking, and shortness of breath. Individuals suffering from SAD often have some degree of insight into their condition, such as recognizing that their fear is excessive or unreasonable (Criterion C); however, despite these insights SAD patients' cognitions are often distorted and maladaptive and therefore seem critical to both the development and maintenance of the disorder. Similar to their fear of negative evaluation, SAD patients often assume that others are making critical judgments about them (e.g. "He thinks that I am stupid”). Maladaptive cognitions of this kind may occur before, during, or after feared social situations, and play an important role in reinforcing fear and promoting avoidant behavior.

Similar to individuals with specific phobias, who go to great lengths to avoid contact with a feared object or situation, people with SAD often try to avoid feared social or performance situations. Avoidance can take on many different forms, not all of which are readily identifiable. While it often manifests as an unwillingness to enter into certain situations and environments, subtler forms of avoidance (e.g., talking on a cell phone or drinking alcohol in social situations) are quite common among SAD patients. When avoidant behavior is not possible, people with SAD often experience great distress and physiological arousal (Criterion D). Avoidance of feared settings and situations critically contributes to the maintenance of SAD, as it supports and reinforces the notion that individuals cannot handle situations on their own and that the situations themselves warrant trepidation. In addition, avoidance prevents people from experiencing positive outcomes incongruent with their maladaptive beliefs and cognitions.

The last diagnostic criterion, Criterion E, states that symptoms must significantly interfere with the affected person's normal routine, or their occupational and social 
functioning. Given the pernicious nature of SAD symptomatology, as well as the ubiquity of social interaction, the disorder often has a profound effect on patients' overall functioning. For instance, unemployment rates are especially high among individuals with SAD and cause marked financial disadvantages (Moitra, Beard, Weisberg, \& Keller, 2011). Similarly, educational attainment rates appear particularly low within this population (Wittchen \& Fehm, 2001). In addition, disruptions in social functioning often cause individuals with SAD to have limited social circles and inadequate support networks (Furmark et al., 1999).

\subsection{Prevalence rates and demographics}

An important source of information concerning the prevalence of mental disorders in the United States is the National Comorbidity Survey (NCS, Kessler et al., 1994) and its replication (NCS-R, Kessler, Chiu, Demler, Merikangas, \& Walters, 2005b). Results from these methodologically sound and large-scale epidemiological studies suggest that approximately 6.8 percent of individuals within the U.S. general population have met diagnostic criteria for SAD in the past year, making it one of the most prevalent mental disorders depicted in the DSM-IV. Estimates of lifetime prevalence suggest that roughly one in eight people (12.1 percent) will, at some point, develop SAD (Kessler et al., 2005a). Despite the general similarity in prevalence rates for SAD across various western societies, including Sweden (Furmark et al., 1999), the Netherlands (Acarturk, de Graaf, van Straten, Have, \& Cuijpers, 2008), and Canada (Offord et al., 1996), there is a remarkable range in prevalence among countries in other parts of the world (see Furmark, 2002 for a review), even those with similar cultural backgrounds. 
SAD has a similar prevalence across the life span, ranging from early adolescence into adulthood (e.g., Chavira, Stein, Bailey, \& Stein, 2004). The average age of onset associated with the disorder is 13 years (Kessler et al., 2005a). Many people who receive a diagnosis of SAD later in life have a history of other related impairments, such as mutism, separation anxiety, behavioral inhibition, and shyness (Chavira \& Stein, 2005). Findings from epidemiological studies indicate that, if left untreated, SAD is typically chronic and unremitting and will lead to substantial impairment in vocational and social functioning (Davidson, Hughes, George, \& Blazer, 1993; Stein \& Kean, 2000).

With regards to sex, evidence from community studies indicates that men and women are affected similarly by the disorder (Moutier \& Stein, 1999); although, results from the NCS-R suggest that prevalence rates may be slightly higher among women (Kessler et al., 2005a). Research examining differences in prevalence across race in the U.S. (Breslau et al., 2006; Grant et al., 2005) suggests that Native Americans are at particularly high risk for $\mathrm{SAD}$, whereas Hispanics and non-Hispanic African Americans seem to be at comparatively lower risk.

\subsection{Cross-cultural, international data}

Given that one defining criterion of SAD is the fear of being scrutinized by others, social norms inherent to different societies could, in principle, produce culturally specific varieties of the disorder. For instance, differences in cognitive styles, (e.g. analytic versus holistic, Nisbett, Peng, Choi, \& Norenzayan, 2001) have been noted when comparing Western and East-Asian societies, and suggest that cognition is intimately connected to culture. Furthermore, a recent cross-cultural study showed that collectivistic countries are 
more accepting toward socially reticent and withdrawn behaviors than was the case in individualistic countries (Heinrichs, Rapee, Alden, Bögels, Hofmann, Oh, \& Sakano, 2006). Moreover, this study found that collectivistic countries reported greater levels of social anxiety and more fear of blushing than individualistic countries.

In the context of SAD, questions of cultural influence can be addressed from different perspectives. One approach is to ask whether the diagnostic criteria included in the DSM-IV have equal validity across cultures. This approach is strongly connected to the previously discussed literature concerning cross-cultural prevalence rates of SAD, which reports inconsistent results. Although some consistency has been observed among several western societies, significantly lower lifetime prevalence rates (around $0.5 \%$ ) have been found elsewhere, such as in Taiwan (Hwu, Yeh, \& Chang, 1989) and Korea (Lee et al., 1990). It remains unclear what mechanisms are responsible for these differences in prevalence.

A second approach to studying SAD cross-culturally is to identify variations in presentation among different populations. In line with this approach, researchers have given attention to the condition Taijin kyofusho (TKS). TKS is found primarily within the context of Japanese and Korean culture, and is characterized by the experience of a single circumscribed fear. The nature of this fear (i.e., the feared object) may change over time for an individual. Examples include blushing, staring, offending others with one's body odors, and presenting an inadequate facial expression or physical deformity (Takahashi, 1989). Although similar to SAD, it has been argued that some aspects of TKS significantly differ. For instance, the TKS "offensive subtype" is characterized by an external focus (i.e. fear of offending others), which contrasts with the internal focus of SAD, in which a fear of being embarrassed is most prominent. 
Despite these differences, however, several studies point to an interrelation between SAD and TKS (e.g. Choy, Schneier, Heimberg, Oh, \& Liebowitz, 2008; Kleinknecht, Dinnel, Kleinknecht, Natsuki, \& Harada, 1997). Kleinknecht et al. (1997) found a significant overlap between SAD and TKS symptoms when assessing American and Japanese students. Similarly, Choy and colleagues (2008) found that $75 \%$ of participants recruited from the US and Korea, and diagnosed with $\mathrm{SAD}$, endorsed at least one of the five symptoms comprising the TKS offensive subtype. Taken together, these findings suggest that, as a construct, SAD generalizes to other cultures, albeit in culturally-nuanced ways. Further research is therefore needed to examine and elucidate other culturally-specific forms of SAD.

In addition to the work being done on TKS, other research efforts have started exploring the impact of several cultural variables (e.g., social norms, gender roles, and selfconstruals) on the manifestation of SAD symptomatology. Reminiscent of the "analytic/holistic" distinction mentioned earlier, differences in terms of "independent" versus “interdependent” self-construals (Markus \& Kitayama, 1991) have been described in the SAD literature. Individuals in Western societies are more likely to have an independent selfconcept, whereas members of Eastern cultures are more likely to endorse interdependent selfconstruals. Cross-cultural research comparing these constructs in relation to SAD (e.g. Okazaki, 1997) suggests that interdependence may be more associated with symptom severity. The relationship of self-construal and social anxiety appears to be further influenced by gender. In men, interdependence and independence has been found to predict levels of social anxiety positively and negatively, respectively, whereas these patterns of association were reversed in women (Moscovitch, Hofmann, \& Litz, 2005). 


\subsection{Comorbidity}

Evidence indicates that the vast majority of individuals suffering from SAD are diagnosed with additional mental disorders. For example, results from the NCS-R (Ruscio et al., 2008) indicate that a lifetime diagnosis of SAD significantly increases the likelihood of meeting criteria for a broad range of other DSM axis-I disorders, most notably other anxiety disorders. Data from the NCS-R suggest that individuals with SAD are between 3 to 9 times more likely to develop a second anxiety disorder at some point in their lives, and appear to be at particularly high risk for agoraphobia without panic; odds ratios comparisons suggest that SAD patients are up to 22 times more likely to develop this particular disorder. Given the prominent role that avoidance plays in the maintenance of SAD, and the tendency for avoidance to progressively worsen over time, it seems that agoraphobic symptoms are conceptually consistent with the phenomenology of SAD.

Interestingly, results from the NCS-R also suggest that risk for comorbidity significantly relates to the number of social fears endorsed. Approximately $63 \%$ of individuals endorsing 1-4 fears met criteria for at least one additional lifetime disorder, while roughly $75 \%$ of participants endorsing 5-7 fears, and 82\% endorsing 8-10 fears, reported comorbid conditions.

One explanation for the considerable amount of comorbidity among SAD patients is the relatively early age of onset associated with the disorder, and the maladaptive coping strategies often employed by individuals with SAD. Patients suffering from SAD commonly report "self-medication" through the use of alcohol and other psychotropic drugs (Bolton, Cox, Clara, \& Sareen, 2006). Using substances such as these to help manage anxiety symptoms can potentially lead to clinically significant levels of substance abuse and 
dependence. Prospective studies examining the temporal onset of SAD and substance use disorders have found SAD to significantly predict subsequent alcohol disorders (Zimmermann et al., 2003). In addition, other prospective studies have found SAD to be predictive of various depressive disorders (Bittner et al., 2004). Additional longitudinal research examining the temporal onset of common comorbid conditions is necessary in order to elucidate the causal relationship between SAD and various other forms of psychopathology.

\subsection{Etiological considerations}

As is the case with most forms of psychopathology, the etiology of SAD appears quite complex, as it seems to be influenced by a number of environmental and genetic factors. Some authors have proposed that, similar to the development of specific phobias, SAD might develop, in part, as a result of experiencing aversive and traumatic incidents. Examples include experiencing perceived social defeats or abasements and being subjected to ridicule and criticism. In addition, evidence suggests that social fears may be learned vicariously by witnessing others' aversive incidents (Öst \& Hugdahl, 1981; Stemberger, Turner, Beidel, \& Calhoun, 1995). In line with behavioral conditioning theories, these studies reported that between $56 \%$ and $58 \%$ of individuals meeting criteria for SAD believe that traumatic social incidents contributed to the development of their feared situations. Another $13 \%$ attributed their fears to some sort of vicarious learning experience. Thus, it appears that some degree of SAD etiology can be attributed to environmental influences. However, other results question the notion that conditioning experiences play a significant role in the etiology of SAD. For 
example, an analysis of the time line suggests that in most cases, the traumatic experience occurs many years after the onset of SAD (Hofmann, Ehlers, \& Roth, 1995).

Evidence for a biological predisposition for and genetic contribution to SAD comes from family studies (Fyer, Mannuzza, Chapman, Liebowitz, \& Klein, 1993; Fyer, Mannuzza, Chapman, Martin, \& Klein, 1995). These show that having relatives diagnosed with SAD significantly increases one's risk of developing pathological social fears. In one study, $23 \%$ of adolescents aged 12-18, whose parents met criteria for SAD, were found to have such fears (Mancini, VanAmeringen, Szatmari, Fugere, \& Boyle, 1996), suggesting significant levels of heritability. In addition, evidence collected as part of a large-scale study using female twins (Kendler, Neale, Kessler, Heath, \& Eaves, 1992) suggests that approximately $30 \%$ of the variance within social-fear-onset can be explained by genetic predisposition, which again stresses the genetic influence for SAD.

Interestingly, while the genetic contributions to social anxiety are often discussed in a nonspecific manner, research suggests that certain heritable temperamental traits are more specifically related to SAD development. For example, one longitudinal study (ChronisTuscano et al., 2009) assessing behavioral inhibition (a temperamental style frequently involving distress or fear in reaction to unfamiliar stimuli, such as peers) among children aged 14 months to 7 years at initial assessment revealed that children who were consistently classified as behaviorally inhibited endorsed significantly higher rates of SAD by age 15 . Thus, while social fear and anxiety appear moderately heritable, mediating factors such as temperament may play a more important indirect role in SAD morbidity.

Looking at SAD from an evolutionary perspective, it has been suggested that social fears results from a biologically determined preparedness to readily connect fear with negative facial expressions, such as anger, rejection, and criticism (Öhman, Dimberg, \& Öst, 
1985). Consistent with this perspective, scientists have observed the use of threatening facial expressions in the social rituals of hierarchically-structured animal groups (Öhman \& Dimberg, 1978). Encounters among these animals often involve displays of anger and threatening facial expressions by dominant group members, as well as fearful and submissive grimaces by defeated counterparts. Social fears are thought to have evolved partly as a byproduct of the social rituals used by animal groups to assign their members to various levels of dominance hierarchies. Interestingly, as noted above, the average age of SAD onset occurs during adolescence, which coincidentally is the developmental stage in which dominanceconflicts are most prominent. Consequently, social anxiety has often been proposed as resulting from a biologically grounded hypersensitivity towards negative facial expressions (Lundh \& Öst, 1996; Mogg \& Bradley, 2002).

\subsection{Cognitive models of social anxiety}

More recently, researchers have been paying close attention to cognitive factors in the development and maintenance of social anxiety (e.g., D. M. Clark \& Wells, 1995; Rapee \& Heimberg, 1997; Trower \& Gilbert, 1989). These models identify a range of biases and distortions in information processing, thoughts, attitudes, and beliefs concerning socially relevant information (for an overview, see D. M. Clark \& McManus, 2002). The cognitive model proposed by Clark and Wells (1995) illustrates the processes suggested to occur when a socially anxious person enters into a feared situation. According to this model, individuals develop various assumptions and beliefs as a result of prior negative social experiences.

These beliefs often include expectations that one will behave in an inappropriate manner, and that such behaviors will lead to ridicule, rejection, or loss of status. Consequently, social 
situations are perceived as dangerous and fear-provoking and often result in the activation of sympathetic arousal. This, in turn, is followed by the perception of various somatic symptoms, such as blushing and rapid heartbeat, which exacerbate feelings of fear. As arousal occurs, attention is shifted inward, away from the external situation and towards the self. As a result, individuals with SAD often miss various social cues within their environment, and interpret this in addition to the catastrophic interpretation of somatic symptoms as further evidence of threat and social failure, which in turn increases the activation of the sympathetic nervous system (see Figure 1). Consequently, to interrupt this vicious circle and to prevent further increases of state anxiety, feared situations are likely to be left and more generally avoided, which in turn leads to increased anticipatory anxiety towards social situations in the future and thus maintains and increases existing social fears in the long term.

\section{Figure 1}

Vicious circle of social anxiety

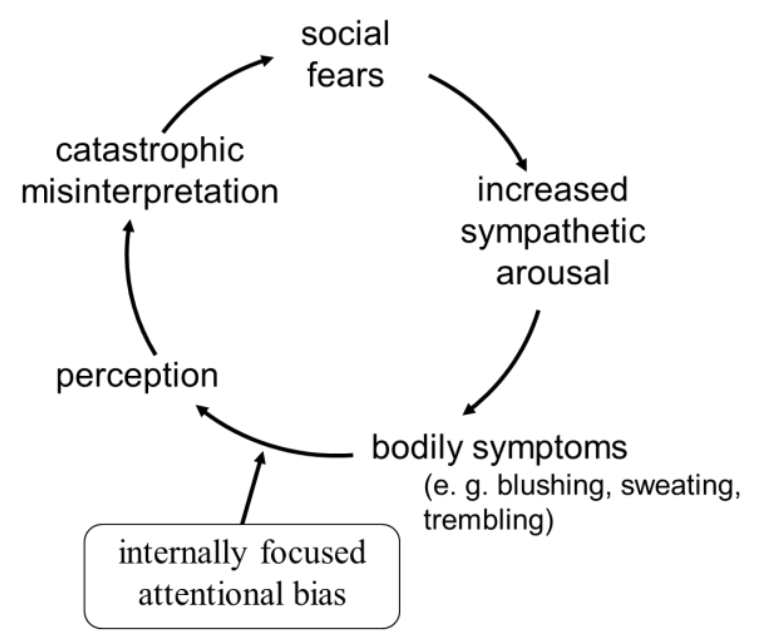

Note: adapted from Gerlach (2005) 
Evidence for cognitive appraisal models comes from several sources. For example, it has been shown that SAD patients show socially relevant judgmental biases prior to treatment, which were attenuated following treatment (Foa, Franklin, Perry, \& Herbert, 1996). In particular, individuals with SAD exaggerate the negative consequences of social mishaps (i.e., the social cost). Similarly, Papageorgiou and Wells (2002) found that, while experiencing symptoms of sympathetic arousal, socially anxious individuals have a tendency to negatively overestimate others' judgments of them. A study conducted by Mulkens and colleagues (1999) suggests that arousal severity may itself be overestimated by socially anxious individuals. In addition, Mellings and Alden (2000) found that socially anxious participants were more likely to focus attention inward while in anxiety-provoking situations. More specifically, it has been found that individuals with SAD show heightened negative self-focused attention (Hofmann, 2000) and negative self-perception (Hofmann, Moscovitch, Kim, \& Taylor, 2004) that changes with successful treatment. Thus, it appears that a number of predictive cognitive processes contribute to SAD patients' fear responses and interpretations in social situations.

\subsection{Cognitive biases in face processing}

In addition to offering explanations of the nature and relationship regarding cognitive processes and physiological reactions within a given feared situation, cognitive models of SAD also suggest more general mechanisms and attributes that lead to the onset and maintenance of social fears. Similar to the evolutionary account for social anxiety (Öhman, 1986) that proposes an underlying hypersensitivity towards specifically negative facial expressions in individuals with SAD (Lundh \& Öst, 1996; Mogg \& Bradley, 2002), cognitive 
models of SAD also imply an underlying biased processing of facial expressions in social anxiety. For instance, Clark and Wells (1995) state that, due to the highly threatening character of negative evaluation for individuals with SAD, respective individuals are strongly motivated to search for information and cues of how other persons view them in a given moment. Since affective states and attitudes are rarely communicated verbally but rather conveyed via facial expressions (Patterson, 1999), the faces of others are perceived as a valid indicator of social acceptance or rejection. Clark and Wells (1995) now argue that an attentional bias towards social threat exists because of the preoccupation with negative selfevaluation in SAD. Furthermore, due to the activated negative self-schemata, ambiguous social information will more likely be interpreted in a negative manner, resulting in an additional interpretational bias in social anxiety. Consequently, according to Clark and Wells' model, specifically ambiguous facial expressions should be interpreted more negatively in social anxiety.

However, other cognitive models propose different interpretational biases. Trower and Gilbert (1989) argue that social anxiety does not only manifest itself in a constant monitoring of one's own behavior but also in a lack of the ability to recognize reassurance and safety signals from others which are intended to increase approach behavior. In other words, socially anxious persons may not optimally perceive signals and hints for safe and cooperative interactions, such as smiles and greetings, and are therefore also more prone to lose "the potentially positive reinforcing and enjoyable attributes of social interaction" (Trower \& Gilbert, 1989, p. 22) as compared to non-anxious persons. Consequently, positive facial expressions should be interpreted as less positive by individuals with SAD.

Lastly, Rapee and Heimberg (1997) stress the importance of attentional mechanisms in social anxiety and distinguish between externally and internally focused attention. In their 
view, an individual with SAD is constantly monitoring a given social situation for possible threats. However, although facial expressions such as frowns are clearly relevant indicators for actual social threats, Rapee and Heimberg specifically emphasize the role of internal cues in social anxiety. According to their model, the sensations of internal autonomic changes (e.g. noticing an increase of the heart rate or feelings of heat) are overestimated in their perceived visibility and interpreted as publicly visible signs of failure, weakness, or incompetence. Moreover, due to the arguably greater objectivity of external information that in turn is less prone to catastrophic misinterpretation, the authors state that external cues for social threat are perceived as less negative and therefore are less relevant for increases in anxiety as compared to internal cues. Consequently, Rapee and Heimberg state the internal focus of attention and the subsequent catastrophic interpretation of bodily signs of arousal as the main mechanism in the development and maintenance of social anxiety disorder. Therefore, face perception and interpretation should not differ as a function of social anxiety levels.

In sum, three different interpretational biases have been suggested in social anxiety to contribute to the development and maintenance of social fears: first, there is the notion of an exaggerated hypersensitivity and a more negative interpretation of especially negative facial expressions in social anxiety (Öhman, 1986); second, an interpretational bias that especially ambiguous faces should be interpreted more negatively (D. M. Clark \& Wells, 1995); and, third, a proposed bias the way that socially anxious individuals should interpret positive facial expressions as more negative (Trower \& Gilbert, 1989). In addition, one model suggests that social anxiety may not be characterized by a biased interpretation of facial expressions at all since especially internal cues and their subsequent interpretation are proposed to mainly contribute to increases in anxiety (Rapee \& Heimberg, 1997). 
Considering that the investigation of interpretational biases of facial expressions in social anxiety does not require invasive procedures or unrealistic setups but instead poses an economically rather feasible design, it is not surprising that many studies to date tried to answer the obvious and intriguing question: "So, which bias is it now"? The following section will give an overview concerning previous research on interpretational biases of facial expressions of social anxiety. 


\section{Interpretation of facial expressions in social anxiety}

To date, the processes of recognition, classification and interpretation as well as more covert behaviors, such as the reallocation of attention to and physiological activation in reaction to various facial expressions, have been investigated extensively with regard to social anxiety (for an overview, see Heinrichs \& Hofmann, 2001; Staugaard, 2010). However, no conclusive results have been obtained to support the notion of a negative interpretation bias for faces as a relevant mechanism in social anxiety. To date, altogether 26 investigations examined possible interpretational biases in samples of socially anxious participants or SAD patients. Interestingly, only four out of these studies found evidence that negative facial expressions were rated as more negative, arousing, unfriendly or unpleasant in the socially anxious groups when compared to non-anxious control participants (Amir, Najmi, Bomyea, \& Burns, 2010; Dimberg \& Christmanson, 1991; Schofield, Coles, \& Gibb, 2007; Straube, Kolassa, Glauer, Mentzel, \& Miltner, 2004). Two additional studies suggested an interpretational bias in socially anxious individuals such that explicitly positive facial expressions were rated as being less friendly or approachable (Campbell et al., 2009; Dimberg, 1997). Finally, three investigations reported findings that socially anxious participants judged neutral faces as more negative or less friendly (Amir et al., 2005; Stevens, Gerlach, \& Rist, 2008; Yoon \& Zinbarg, 2007). However, the majority of results did not suggest an interpretational bias in the judgment of facial expressions, as thirteen of the 26 studies did not find any group differences on valence ratings when negative, neutral, or positive facial expressions were evaluated by socially anxious and control participants (Coles \& Heimberg, 2005; de Jong, Merckelbach, Bogels, \& Kindt, 1998; Evans et al., 2008; Heuer, Rinck, \& Becker, 2007; Lange et al., 2011; Lange, Keijsers, Becker, \& Rinck, 2008; Lissek 
et al., 2008; Merckelbach, Vanhout, Vandenhout, \& Mersch, 1989; Mühlberger et al., 2009;

Stein, Goldin, Sareen, Zorrilla, \& Brown, 2002; Vrana \& Gross, 2004; Wieser, McTeague, \& Keil, 2011; Wieser, Pauli, Weyers, Alpers, \& Mühlberger, 2009). A summary of these patterns can be inspected in Table 1. The following sections will give a more detailed description of the respective results and corresponding experimental paradigms used in the individual investigations.

\section{Table 1}

Ratings of facial expressions: replicated group effects between HSA and controls to date

$$
\text { Pattern } 1 \quad \text { Pattern } 2 \quad \text { Pattern } 3 \quad \text { Pattern } 4
$$

\begin{tabular}{|c|c|c|c|c|}
\hline Negative facial expressions & $\begin{array}{c}\text { HSA: more } \\
\text { negative }\end{array}$ & n.s. & n.s. & n.s. \\
\hline Neutral facial expressions & n.s. & $\begin{array}{l}\text { HSA: more } \\
\text { negative }\end{array}$ & n.s. & n.s. \\
\hline Positive facial expressions & n.s. & n.s. & $\begin{array}{c}\text { HSA: more } \\
\text { negative }\end{array}$ & n.s. \\
\hline $\begin{array}{l}\text { Number of studies that found } \\
\text { this pattern }\end{array}$ & 4 & 3 & 2 & 13 \\
\hline
\end{tabular}

\subsection{Biased interpretation of negative facial expressions in}

\section{social anxiety}

As one of the first studies assessing interpretational biases of facial expressions in social anxiety, Dimberg and Christmanson (1991) investigated samples high and low fearful public speaking individuals and asked them to rate the emotional valence, friendliness, 
hostility, and directedness of facial pictures. As stimuli, the authors chose the happy and angry faces from a widely used picture set generated by Ekman and Friesen (1976). This larger database, the so-called "Pictures of Facial Affect", consists of grey-scaled photographs capturing the faces of five men and six women, all of them Caucasian, who display each of the six basic facial expressions (happiness, sadness, anger, fear, disgust, and surprise; Ekman \& Friesen, 1971) and a neutral expression. Interestingly, Dimberg and Christmanson (1991) found participants with self-reported high fears of public speaking to rate specifically angry faces as more negative as compared to the low-anxious control group.

Similarly, Straube and coauthors (2004) assessed SAD patients and mentally healthy control participants by employing ratings of valence and arousal towards facial expressions. In this investigation, neutral and angry expressions of nine male and nine female Caucasian individuals were used as facial stimuli. Both SAD patients and control subjects rated angry faces as more arousing and unpleasant as compared neutral faces. Furthermore, an interaction of group and facial expression was revealed the way that SAD patients rated angry faces as more arousing as non-anxious participants did.

Schofield and colleagues (2007) investigated students with high and low fears of negative evaluation. As stimuli, the authors implemented happy, disgust, and neutral pictures from Matsumoto and Ekman's (1988) Japanese and Caucasian Facial Expressions of Emotions. To allow for more variation in emotion intensity, the authors created morphed images that combined a neutral and an emotional expression to a predefined degree; e.g. a respective stimulus could represent a neutral expression to $30 \%$ and a disgust expression to $70 \%$. Participants were asked to identify the respective emotion and to rate the emotional cost for a hypothesized social interaction by indicating "what it would be like to interact with someone looking at me this way" on a scale ranging between the anchors "it would be very 
bad for me" and "it would be very good for me". Although high and low fear of negative evaluation groups did not differ in their accuracy of emotion identification, high fear subjects rated the hypothesized social interactions with specifically disgust expressions as more negative. This effect was found to be independent of actual emotion intensity of the facial expression.

In the same vein, Amir and coauthors (2010) assessed valence ratings towards disgust and anger expressions in samples of socially anxious participants, non-anxious controls, and a generally dysphoric and anxious (but not socially anxious) group that matched the socially anxious sample in terms of trait anxiety and depression. Similar to the findings of Schofield and colleagues (2007), the disgust faces were rated more negatively by the socially anxious participants whereas the control groups did not differ in their ratings for the disgust and anger faces.

\subsection{Biased interpretation of neutral facial expressions in}

\section{social anxiety}

In contrast to the reported findings of a negative bias regarding specifically facial expressions of disgust in social anxiety (Amir et al., 2010; Schofield et al., 2007), a previous study conducted by Amir and colleagues (2005) did not find a more negative interpretation of disgust expressions. The authors assessed eleven treatment-seeking patients with SAD and eleven mentally healthy control subjects by presenting facial expressions of disgust and neutral faces. Participants rated the emotional valence of each stimulus. However, although the SAD group was generally faster in rating disgust expressions as compared to the control 
group, no difference in the ratings of emotional valence emerged between the groups. Instead, the SAD group was found to rate specifically neutral faces as more negative.

Yoon and Zinbarg (2007) chose different experimental methods for assessing interpretational biases of facial expressions in social anxiety. First, the authors implemented a correlational approach and included 51 unselected students in their investigation. To obtain an index of social anxiety, participants were asked to complete respective questionnaires at the beginning of the experiment. Second, the study task differed from the previously described investigations insofar that participants were asked to make up short stories in their response to facial stimuli. Pictures of angry, disgust, happy and neutral faces (Ekman \& Friesen, 1976) were used in the investigation. Response stories had to contain the feeling of the person in the picture (i.e., he looks happy because he got a good grade). Interestingly, a significant correlation was revealed for the interpretation of specifically neutral stimuli and social anxiety: the higher participants scored on social anxiety measures, the more threatening were their interpretations of the neutral stimuli.

Lastly, Stevens, Gerlach, and Rist (2008) found a negative interpretation bias of neutral facial expressions in social anxiety. The authors included 40 treatment-seeking SAD patients and 40 mentally healthy control participants in their study. As stimuli, happy, angry, and neutral facial expressions adapted from Lundqvist, Flykt, and Öhman (1998) were used. In addition, the authors implemented morphed pictures that blended $33 \%$ of the respective emotional expression with $66 \%$ of a neutral expression. Participants were instructed to imagine the respective stimuli in a conversational situation and were told to indicate how friendly (versus rejecting) they perceived the individual faces. However, groups were not found to differ in their interpretation of any morphed condition. Instead, SAD patients were 
shown to rate neutral faces as less friendly (or more rejecting) as compared to the control group.

\subsection{Biased interpretation of positive facial expressions in}

\section{social anxiety}

An interpretational bias the way that safety signals and, in consequence, positive facial expressions, are overlooked or ignored in social anxiety disorder, as proposed by Trower and Gilbert (1989), was revealed by two studies to date. First, Dimberg (1997) investigated low and high fear of public speaking groups by gathering their ratings of anger, hostility, happiness, friendliness, and directedness towards angry and happy facial expressions (Ekman \& Friesen, 1976). Both groups rated happy expressions as appearing more happy and friendly whereas angry faces were perceived as more angry and hostile. However, the high fearful group rated the happy expressions as less happy and friendly as compared to the low fearful group. In addition, high fearful subjects rated happy faces as significantly more hostile as compared to the low fearful participants.

A similar result was obtained by Campbell and colleagues (2009). The authors assessed twelve SAD patients and 28 mentally healthy control participants. The task in this investigation consisted in rating facial expressions of happiness, disgust, and anger (Matsumoto \& Ekman, 1988) on approachability (i.e., "rate how likely you are to approach and engage the presented person (face) in a social interaction"). A significant main effect of group indicated that the SAD sample rated all stimuli as less approachable than the control group. In addition, a significant interaction between group and emotional expression was 
found. Post-hoc tests revealed that the SAD group rated specifically happy faces as less approachable as compared to healthy control participants.

\subsection{Discussion and integration of results to date}

Taken together, most of the research conducted on interpretation of emotional facial expressions did not reveal a specific interpretation bias in social anxiety. Two further studies (not included in Table 1) found a generally more negative evaluation of facial expressions in socially anxious individuals (Furmark et al., 2009; Goldin, Manber, Hakimi, Canli, \& Gross, 2009); however, no control condition was implemented in these two investigations. Also, a study conducted by Dimberg and Thunberg (2007) revealed a significant interaction of social anxiety and facial expression on subjects' ratings of disgust and unpleasantness, which, however, were not statistically followed up any further. Finally, Straube et al. (2005) reported a deviant result in that socially anxious participants evaluated happy faces as more pleasant as compared to non-anxious control persons.

Unfortunately, the majority of these ratings was gathered as a subsequent add-on to a more extensive experiment or in the context of measurements of physiological parameters (Staugaard, 2010). For example, some authors implemented the self-ratings as an addition to a functional magnetic resonance imaging (fMRI) task (Evans et al., 2008; Stein et al., 2002; Straube et al., 2004; Straube et al., 2005) or to a study collecting electromyogram (EMG) or electroencephalogram (EEG) data (Dimberg \& Thunberg, 2007; Mühlberger et al., 2009; Wieser et al., 2011). Upon completing the physiological recordings, the same stimuli used in the main task were then presented to the participants again to gather reports of perceived valence. Obviously, such a sequential procedure has a number of disadvantages. For example, 
after engaging in long protocols, participants may have experienced fatigue and their waning attention could have impacted the rating task. Furthermore, the repeated exposure to the same faces may have led to habituation that might have affected these ratings.

Nonetheless, the overall picture does not become more consistent when focusing on studies without more invasive physiological procedures. For instance, Yoon and Zinbarg (2007) as well as Stevens and co-authors (2008), revealed a more negative interpretation of neutral faces in socially anxious participants and SAD patients, while Lange and colleagues (2008) did not show any effects of social anxiety on self-rated valence and arousal in response to emotional face stimuli. Amir and coauthors (2010) found that socially anxious participants were more likely to rate facial expressions of disgust as more negative than control participants, yet another pattern of results.

Another shortcoming of previous studies may be related to the type of rating that participants were required to give in the respective investigations. Many studies asked for simple ratings of valence and/or arousal (Amir et al., 2005; Amir et al., 2010; Evans et al., 2008; Heuer et al., 2007; Merckelbach et al., 1989; Mühlberger et al., 2009; Straube et al., 2004; Wieser et al., 2011; Wieser et al., 2009). From a psychopathological perspective, these judgments may not necessarily tap into the phenomenology of social anxiety. Arguably, it would be preferable to obtain ratings of face stimuli on a dimension with direct relevance for the social context, not just a general rating of valence or arousal. However, only few studies tested differences on such a dimension: For example, Campbell and co-authors (2009) asked participants to rate the "approachability" of facial pictures with various emotional expressions and found patients diagnosed with SAD to rate happy faces as less approachable than non-anxious controls. Similarly, Stevens and colleagues (2008) investigated ratings of perceived friendliness toward the observer. 
Taken together, the research of interpretational biases in social anxiety disorder might benefit from implementing a design that allows for the assessment of interpretations without too tedious, invasive, or time-consuming protocols in order to minimize habituation and fatigue of participants. Second, the assessment of a more socially relevant characteristic seems promising: instead of implementing valence or arousal judgments, the assessment and examination of a dimension that relates more directly to social approach or avoidance behavior may be helpful in order to clarify the heterogeneity of previous results. 


\section{$4 \quad$ Testing hypotheses or testing the data?}

A broader and more general shortcoming of the previously mentioned results lies in the testing strategy that the respective studies applied. The so-called "Null Hypothesis Significance Testing" (NHST; Cohen, 1994) that is inherent to the vast majority of commonly conducted and reported statistical inference tests, such as ANOVA and regression designs, "has not only failed to support the advantage of psychology as a science but also has seriously impeded it" (Cohen, 1994, p. 997). To understand the reasons for applying NHST in the first place and to comprehend the issues and problems related to its current use, the next sections will give a short excursus into this matter and also introduce a theoretical basis for an analytical framework that tries to work around the known shortcomings of NHST.

\subsection{The principle of falsification}

The strength and the core reason for today's use of NHST lies in its original function to validly demarcate science from pseudoscience and is therefore applied to promote and expand scientific knowledge. The scientific-philosophical basis for NHST was created by Karl Raimund Popper (1902-1994) who introduced the concept of "critical rationalism" (Popper, 1935) in response to earlier accounts of philosophy of science, most importantly the "logical empiricism", as was advocated by the Vienna Circle (see also the Tractatus, Wittgenstein, 1921). Logical empiricists argued that a scientific theory can be validated only by verification, which means gathering observable evidence in order to induce a more general or abstract rule. Consequently, scientific progress results from the degree of verification of a given hypothesis: the more empirical support can be found for a specific hypothesis, the higher is its prognostic value and validity in relation to future observations. Popper now 
criticizes the actual validity of the induction principle by stating this often cited example (Popper, 1935, p. 3): regardless of how many white swans have been observed, one can never arrive at the general rule "all swans are white" since the existence of one single black swan suffices to disprove this rule - and black swans do indeed exist. Consequently, even if uncountable observations exist in favor of a specific theory, they won't suffice to verify a theory since there is always the possibility of deviant observations. In other words, it is logically impossible to induce the validity or truth of a given hypothesis. Obviously, the problem arising from the deficiency of the induction principle lies in the now recurrent need to demarcate empirical scientific theories from non-empirical or non-scientific theories, such as mathematical and logical statements as well as metaphysical assumptions and claims.

Popper's own approach, as he states himself, is “in schärfstem Widerspruch zu allen induktionslogischen Versuchen" (approximately: in the strongest conflict to all attempts of induction; Popper, 1935, p. 5), in which he is advocating the deductive method of investigation. Within his philosophical-scientific framework, Popper first introduced four more general guidelines as propositions for the logical and empirical testing of theories and hypotheses. According to Popper, the sound investigation of theories should always be conducted in four different directions: (1) the logical consequences of a given theory should be compared so that contradictions within the theory can be investigated; (2) the logical form of the theory should be investigated with respect to its empirical-scientific claim (that is, the theory under investigation should not be tautological); (3) the theory under investigation should be compared to other theories with respect to the question whether the new theory actually marks scientific progress; and (4), the core feature of Popper's deductive approach, the theory should be investigated by empirical applications of its deduced implications. The following section will explain the logical rationale of the deductive empirical investigation in 
more detail. However, it is important to note that even if a theory passes all these tests, it is considered to be only preliminary validated or, otherwise, falsified. According to Popper, any form of validation can only be preliminary. Theories can never be proven to be definitely true, valid, or even likely.

The formal notion of testing the deduced application can be expressed in terms of propositional logic: a prognosis or prediction $\mathrm{P}$ is deduced from a theory or hypothesis $\mathrm{T}$ so that when $\mathrm{T}$ is true, also the statement $\mathrm{T} \rightarrow \mathrm{P}$ is true and $\mathrm{T}$ thus implies $\mathrm{P}$. Now an observation of "not-P" $(\ulcorner\mathrm{P})$ is made, which implies "not-T" $(\ulcorner\mathrm{T})$. An example for this is $\mathrm{T}$ : it is raining; and P: the street is wet. Now it is observed that the street is dry, which is $\sim \mathrm{P}$. Consequently, it does not rain, $-\mathrm{T}$. This specific rule of inference, " $\mathrm{T} \rightarrow \mathrm{P}$ implies $\sim \mathrm{P} \rightarrow$ $-T^{\prime}$, is called modus tollens. The important point here is that one cannot simply imply from an observation $\mathrm{P}$ that also $\mathrm{T}$ is valid: based on the fact that the street is wet, it cannot be concluded that it is raining. The street could also be splashed by someone or something else. Spoken more generally, different scenarios or theories can also imply the prognosis $\mathrm{P}$. The only logical inference can be made from $\sim \mathrm{P}$ to $\ulcorner\mathrm{T}$. This issue constitutes the formal background for the cardinal impossibility of the induction principle and, in consequence, accounts for the impossibility of verifying a theory. According to Popper, the only way of scientific progress consists in the falsification of deduced hypotheses.

In summary, the main conclusions resulting from Popper's theoretical considerations are the following:

1. It is simple to obtain confirmation or verification for nearly all theories if one is specifically looking for confirmation.

2. Confirmations should only count if they emerge as a result from risky observations, that is, if an outcome is expected that is incompatible 
with the theory. For example, risky observations may result from novel and thus tentative applications of the theory, whereas replicating a previous result is not considered to be a risky observation. The compatible outcome of a risky observation then falsifies the expectancy and in turn preliminary validates the theory.

3. Every "good" theory is prohibition: it prohibits the occurrence of specific observations and thus consists of actual testable statements and claims. The more a theory prohibits the better (for) the theory since its empirical applications can be tested more widely.

4. A theory that cannot be falsified is nonscientific. Infallibility is not a virtue but a vice.

5. Every real test of a theory is an attempt to falsify it. Testability is falsifiability, but there are various degrees of testability. Some theories are more testable and are thus more objected to falsification as others. These theories have a higher risk.

6. Verifying or confirming evidence has no meaning unless it is resulting from a real test of the theory. This evidence is then the result of a legitimate but unsuccessful attempt to falsify it.

7. Some actually testable theories are often kept by their advocates although they have been falsified. To save the respective theory, some ad-hoc statements are introduced that make the theory seem compatible with the data, or the theory is interpreted in a different way to appear compatible to the data. According to Popper, ad-hoc 
adjustments are always possible, but they eradicate the scientific status of the theory.

Popper argues that Albert Einstein's theory of relativity (1916) is a good example of a proper (that is, well testable) scientific theory. Based on the theory, Einstein predicted that light is distracted as a result from the sun's gravitational effects (see also Einstein, 1911). In 1919, Arthur Eddington travelled to Principe (Gulf of Guinea, West Africa) to observe an eclipse and to investigate whether the positions of the stars indeed deviated as predicted by Einstein's theory. In fact, the observed deviations corresponded with the prediction (Dyson, Eddington, \& Davidson, 1920). Popper stresses that this test constituted a high risk for the theory: if the proposed deviation was not observed, the theory had to be condemned because it had been incompatible with possible results from empirical observations. However, note that this observation does not result in the ultimate verification of Einstein's theory. Moreover, Popper argues that Einstein's theory is just preliminary validated and still should be condemned if future observations indeed deviate from the hypothesized predictions. According to Popper, a scientific theory is not considered good because it is not rejected; moreover, a good scientific theory is characterized by a high degree of testability and its permission for risky observations.

\subsection{Null hypothesis significance testing}

Resulting from Popper's notion of falsification being the only means of enabling scientific progress, today's empirical sciences heavily rely on this concept and operationalized Popper's rather philosophical thoughts into inference statistical methods that explicitly test a given theory: let $H_{0}$ be a specific hypothesis and let $H_{1}$ be the antithesis that 
implies the invalidity of $H_{0}$. Now the actual validity (or better: the likelihood of the invalidity) of $H_{0}$ has to be determined by empirical observation. However, to the extent that $H_{1}$ and $H_{0}$ transcend the data, this decision cannot be made with absolute certainty. Moreover, two kinds of wrong decisions can be made. First, one can reject the $H_{0}$ and in turn choose $H_{1}$ although $H_{0}$ is actually true, which is called Type I error or alpha error. Second, the $H_{0}$ can be kept and accepted as being true although it is in fact false, which is a Type II or beta error. Alpha and beta indicate the likelihood for making the specific error (therefore, the expressions "alpha and beta error" can be misleading) whose precise values are determined by both the data and a decision criterion. The decision criterion in turn is a result of probabilistical and thus mathematical considerations on the one hand, and considerations regarding the implications of an erroneous decision on the other hand. In empirical sciences, the decision criterion is usually set to an alpha level of 0.05 , indicating that the likelihood of falsely rejecting the $H_{0}$ is five per cent at the most.

The practice of null hypothesis significance testing (NHST) has been criticized for quite essential reasons. Already in 1966, Bakan pointed out that NHST's actual use is "hardly original" and mostly used to statistically account for well-known facts, therefore leading to stagnation of the scientific progress. In the same vein but more metaphorically, Meehl (1967) described NHST to be "a potent but sterile intellectual rake who leaves in his merry path a long train of ravished maidens but no viable scientific offspring" (p. 265). In addition, the common conclusion that the rejection of $H_{0}$ establishes the actual theory (i.e., the $H_{1}$ ) is critical when reflecting the logical impossibility of verifying a hypothesis. Note that this statement does not contradict the validity of Popper's approach of falsification: according to Popper, the $H_{0}$ should reflect the theory to be tested so that valid conclusions can be drawn regarding its (non-)application on the given data. This, however, is hardly ever done in 
psychological research where the $H_{1}$ usually constitutes the actual theory and the $H_{0}$ reflects a more or less meaningless counterpart.

Nonetheless, the maybe most important problem lies in the research question asked by the vast majority of empirical studies: "Given these data $(D)$, what is the probability that $H_{0}$ is true?"(Cohen, 1994, p. 997), which can be written as $P\left(H_{0} \mid D\right)$. Although Cohen points out that this indeed is the crucial research question every scientist wants to answer, he states that NHST is not the means to obtain it. Moreover, NHST gives an answer to the following question: "Given that $H_{0}$ is true, what is the probability of these (or more extreme) data?", which is $P\left(D \mid H_{0}\right)$. This common confusion leads to a major difference in the statistical reasoning process. To clarify this issue, consider the following example of an experimental study of individuals with high and low levels of social anxiety who rated facial stimuli, just as reviewed in the previous chapter. Obviously, the null hypothesis constitutes the independence between facial evaluation and social anxiety scores while the $H_{1}$ states an effect of social anxiety on facial ratings:

$H_{0}$ : Individuals high and low in social anxiety do not differ in their interpretation of facial stimuli.

$H_{1}$ : Individuals high and low in social anxiety do differ in their interpretation of facial stimuli.

Now imagine that indeed a statistically significant difference between the two groups was obtained, which can be written as $P\left(D_{\text {observed }} \mid H_{0}\right)<.05$. To put in other words, this finding means that given that $H_{0}$ (both groups do not differ) is true, the occurrence of the specific result $D$ (the observed difference on facial ratings between the groups) is very unlikely. However, this interpretation will not be made. Moreover, the researcher wants to reject the $H_{0}$ (and not the data!) in the way that the observed result will be interpreted as 
follows: given these results, the validity of $H_{0}$ is unlikely and therefore differences between high and low anxious individuals exist. This, however, is the inverse probability $P$ $\left(H_{0} \mid D_{\text {observed }}\right)$. And unfortunately, the two different probabilities $P\left(D_{\text {observed }} \mid H_{0}\right)$ and $P$ $\left(H_{0} \mid D_{\text {observed }}\right)$ are not the same in neither their arithmetical procedures nor their interpretational conclusions. Mathematically, the relationship between the general forms of these probabilities can be expressed with the following equation, which is also known as the Bayes' theorem (Jeffreys, 1935):

$$
P\left(H_{0} \mid D\right)=\frac{P\left(H_{0}\right) \cdot P\left(D \mid H_{0}\right)}{P(D)}
$$

The terms $P\left(H_{0}\right)$ and $P(D)$ reflect the so-called "prior probabilities", or the initial degrees of belief, in the Null hypothesis $\left(H_{0}\right)$, and in a significant outcome $(D)$. Because $H_{0}$ and $H_{1}$ are complementary events, this equation can be further specified with respect to the unknown parameter $P(D)$ :

$$
P\left(H_{0} \mid D\right)=\frac{P\left(H_{0}\right) \cdot P\left(D \mid H_{0}\right)}{P\left(H_{0}\right) \cdot P\left(D \mid H_{0}\right)+P\left(H_{1}\right) \cdot P\left(D \mid H_{1}\right)}
$$

Usually, the probabilities of the prior hypotheses $P\left(H_{0}\right)$ and $P\left(H_{1}\right)$ are unknown as well. However, to highlight the problems of the common NHST interpretation, consider the following numerical example by estimating $P\left(H_{0}\right)$ and $P\left(H_{1}\right)$ from the previous research on this specific topic: nine out of 22 studies found a difference between socially anxious and non-anxious participants in facial interpretations, resulting in $P\left(H_{1}\right)=\frac{9}{22} \approx 0.41$. In addition, 13 of the 22 studies did not find a significant difference on the same research question, therefore leading to $P\left(H_{0}\right)=\frac{13}{22} \approx .59$.

In addition, $P\left(D \mid H_{1}\right)$ and $P\left(D \mid H_{0}\right)$ can be estimated by assuming the sensitivity and specificity parameters for the used methodology. Since the sensitivity of a test indicates the 
probability of rejecting $H_{0}$ given that $H_{1}$ is actually true, the term $P\left(D \mid H_{1}\right)$ equals this definition exactly. On the other hand, the specificity of a given test is defined by the probability of keeping the $H_{0}$ given that $H_{0}$ is actually valid, which is expressed as $P\left(\neg D \mid H_{0}\right)$ where $\neg D$ means "not-D", that is, a negligible and thus non-significant difference between the respective groups. Since $\neg D$ and $D$ are complementary events, $P\left(D \mid H_{0}\right)+P\left(\neg D \mid H_{0}\right)=$ 1 and therefore $P\left(D \mid H_{0}\right)=1-P\left(\neg D \mid H_{0}\right)$; in other words: $P\left(D \mid H_{0}\right)$ can be calculated by subtracting the test's specificity from 1 .

To follow the numerical example, assume a sensitivity of $P\left(D \mid H_{1}\right)=.8$, which is a reasonable value since experimental study designs and tasks usually have a quite high sensitivity (or a high power, which is mathematically the same). On the other hand, and due to the interdependence of alpha and beta errors, the specificity of experimental tests is often smaller. Therefore, let the specificity of the test be $P\left(\neg D \mid H_{0}\right)=.5$ so that $P\left(D \mid H_{0}\right)=1-$ $P\left(\neg D \mid H_{0}\right)=.5$ as well.

With now all unknown variables set or estimated, the equation in order to obtain $P\left(H_{0} \mid D\right)$ can be solved:

$$
\begin{gathered}
P\left(H_{0} \mid D\right)=\frac{P\left(H_{0}\right) \cdot P\left(D \mid H_{0}\right)}{P\left(H_{0}\right) \cdot P\left(D \mid H_{0}\right)+P\left(H_{1}\right) \cdot P\left(D \mid H_{1}\right)} \\
\Leftrightarrow P\left(H_{0} \mid D\right)=\frac{.59 \cdot .5}{.59 \cdot .5+.41 \cdot .8} \\
\Leftrightarrow P\left(H_{0} \mid D\right)=.47
\end{gathered}
$$

In other words, this numerical example implies that when obtaining a significant difference between socially high and low anxious participants regarding interpretation of facial stimuli so that $P\left(D \mid H_{0}\right)<.05$, it can be interpreted the way that this result is very unlikely given that $H_{0}$ is true. However, given this example, the likelihood that the null hypothesis is actually true is in fact quite substantial because $P\left(H_{0} \mid D\right)=.47$ ! This contrast 
highlights the obviously problematic but very common interpretation of $P\left(D \mid H_{0}\right)$ and thus questions more generally the inferences and implications of NHST. According to Cohen (1994), especially when the $H_{1}$ equals the theory or the outcome that the researcher wishes to observe (and which is in contrast to Popper's original use of falsification, where the $H_{0}$ constitutes the theory), Bayesian priors should always be taken into account when inferring the appliance of $H_{0}$.

Another broad concern results from the operational definition of commonly used null hypotheses. Usually, the null hypothesis simply states the complete absence of any relationships or dependences between IVs and DVs so that the respective effect size is set to $\mathrm{ES}=0$ (Cohen, 1994). Cohen points out that this zero-parameterization of the $H_{0}$ commonly leads to rejection, even when implementing only small samples. Moreover, as Lykken mentioned already in 1968 , "Unless one of the variables is wholly unreliable so that the values obtained are strictly random, it would be foolish to suppose that the correlation between any two variables is identically equal to $0.0000 \ldots$ (or that the effect of some treatment or the difference between two groups is exactly zero).” (pp. 152-153). Consequently, due to random influences and measurement errors, an "ambient noise level" of shared variance between the supposedly unrelated variables will be detected (see also Meehl, 1990). Especially when implementing larger samples, these small correlations will quite likely emerge as significantly different from a specified $H_{0}$ of $r=0$, which is nonetheless a meaningless result. Thus, more specified null hypotheses (such as $H_{0}: r<.2$ ) instead of the simple "nil hypothesis" of ES = 0 (Cohen, 1994) should be investigated in order to obtain more profound and interpretable results.

Another important criticism regarding the common practice of accepting or rejecting the null hypothesis is based on the dichotomous criterion value, which is usually set to $p<$ 
.05. As pointed out by Rosnow and Rosenthal (1989), "God loves the .06 nearly as much as the .05. Can there be any doubt that God views the strength of evidence for or against the null as a fairly continuous function of the magnitude of $p$ ?” (p.1277). In the same vein, Tukey (1969) argues that the progress of science is based upon piling up amounts, and not just directions, of empirical evidence. As Cohen puts it, "But if all we, as psychologists, learn from research that $\mathrm{A}$ is larger than $\mathrm{B}(p<.01)$, we have not learned very much. And this is typically all we learn." However, to address this problem, the notion of effect sizes in addition to the NHST's mere $p$ value has become an essential requirement for psychological publications in the recent past (APA, 2010). Nonetheless, as pointed out by Kelley and Preacher (2012), the term effect size is still used inconsistently, and reported effect sizes are often interpreted insufficiently.

To summarize the critical aspects of NHST, it has been reviewed that

1) Bayesian priors should be implemented in the statistical process to arrive at a proper interpretation of statistical inferences,

2) Null hypotheses should specify concrete and non-zero parameters since the absolute independence between variables is highly improbable.

3) A proper description and interpretation of the amount of evidence is as important as its direction.

The next paragraph will give a brief overview of a new statistical method that tries to work around the known shortcomings of NHST and thus provides a different approach to test the magnitude of relationships between IVs and DVs: the Bayesian evaluation of informative hypotheses (Hoijtink, 2012). 


\subsection{Bayesian evaluation of informative hypotheses}

The Bayesian method of "significance testing" was first introduced by Sir Harold Jeffreys $(1935,1961)$. His work offered a new approach of testing two specific hypotheses against each other by employing the so-called Bayes Factor $(B F)$, which can be interpreted as a quantitative representation of the degree of evidence in favor of a respective hypothesis. The mentioned Bayes' theorem constitutes a major aspect of its mathematical basis. In more detail, the $B F$ for two competing hypotheses $H_{1}$ and $H_{2}$ in an empirical dataset $D$ is defined as the quotient of the probability densities $p r$ that indicate the degree of evidence in the data according to each of the hypotheses (Kass \& Raftery, 1995):

$$
B F_{1,2}=\frac{\operatorname{pr}\left(D \mid H_{1}\right)}{\operatorname{pr}\left(D \mid H_{2}\right)}
$$

When reviewing the Bayes' theorem and assigning probability densities $p r$ instead of fixed $P$ values, the multiplication of the Bayes' theorem with the $B F$ leads to the following equation:

$$
\frac{\operatorname{pr}\left(H_{1} \mid D\right)}{\operatorname{pr}\left(H_{2} \mid D\right)}=\frac{\operatorname{pr}\left(H_{1}\right)}{\operatorname{pr}\left(H_{2}\right)} \cdot B F_{1,2}
$$

To illuminate the interpretation, the Bayes factor can be considered as the ratio of the posterior odds $\operatorname{pr}\left(H_{k} \mid D\right)$ to its respective prior odds $\operatorname{pr}\left(H_{k}\right)$ with $k=(1,2)$. In the case that the prior odds of the two hypotheses are equal, the $B F$ can be derived directly from the respective posterior odds. However, note that this approach specifically incorporates the possibility of unequal (and thus to be considered!) priors, as was neglected and consequently criticized in NHST's methodology. The $B F$ is then obtained by integrating the densities $\operatorname{pr}\left(H_{k} \mid D\right)$ and $\operatorname{pr}\left(H_{k}\right)$ over the parameter space. For a more detailed description of how the 
parameters are estimated, see Hojitink (2012) and van den Schoot and colleagues (2011) for comprehensive overviews.

Another important difference to NHST is that the $B F$ allows for the simultaneous comparison of multiple specific, or informative, hypotheses (van de Schoot et al., 2011) so that pre-defined constraints can be implemented on the parameters of interest (such as $H_{1}: \mu_{1}$ $<\mu_{2}<\mu_{3}=\mu_{4}$ versus $H_{2}: \mu_{1}=\mu_{2}>\mu_{3}=\mu_{4}$ ) which can be tested directly against each other. Also, note that the hypotheses under investigation do not have to be mutually exclusive. On the other hand, in NHST, only unconstrained hypothesis can be tested against its logical counterpart (such as $H_{0}: \mu_{1}=\mu_{2}$ versus $H_{1}: \mu_{1} \neq \mu_{2}$ ). Although employing contrasts is a helpful strategy to test more informative constraints within NHST (Rosenthal, Rosnow, \& Rubin, 2000), still only one single hypothesis can be tested at a time and thus leads to problems such as the need for corrections regarding multiple testing and comparability difficulties in designs comparing multiple hypotheses (Cooper, 2012).

As Kass and Raftery (1995) state, "the Bayes factor is a summary of the evidence provided by the data in favor of one scientific theory, represented by a statistical model, as opposed to another" (p. 777). In Table 2, Kass's and Raftery's guidelines for interpreting the size of the $B F$ can be depicted. However, it is important to note that these guidelines, although they have an intuitive appeal, are not well founded (see also De Santis, 2004; Garcia-Donato \& Chen, 2005). Also, Hoijtink (2012) argues that the categories of the degree of evidence are rather fuzzy. Nonetheless, these guidelines might be helpful in terms of roughly describing and comparing the amount of evidence obtained by the $B F$. 


\section{Table 2}

Interpretation guidelines for Bayes Factors

Size of BF Degree of evidence

\begin{tabular}{cc}
\hline $1-3$ & Not worth more than a bare mention \\
$3-20$ & Positive \\
$20-150$ & Strong \\
$>150$ & Very strong \\
\hline
\end{tabular}

Note: Adapted from Kass and Raftery, 1995 (p. 777).

However, from a philosophical background, it can be argued that the Bayesian approach, and especially the interpretation of the $B F$ as the degree of evidence in favor of a specific theory, incorporates inductive inferences and thus follows the verification "principle". This, as noted above, has been proven to omit a solid logical foundation (Popper, 1935). Jeffreys (1961) now argues that NHST is certainly applicable in cases that a clear-cut theory, like Einstein's relativity theory, is tested for its empirical relevance. Nonetheless, a rigid rejection in case that the data "falsifies" the theory also leads to problems when considering the scientific progress: "Is it of the slightest use to reject a hypothesis until we have some idea of what to put in its place? If there is no clearly stated alternative, and the null hypothesis is rejected, we are simply left without any rule at all, whereas the null hypothesis, though not satisfactory, may at any rate show some sort of correspondence with the facts."(p. 390). Moreover, Jeffrey argues that the scientific progress builds on imperfect theories which do indeed deviate from empirical observations. Nonetheless, as far as the deviations are considered sufficiently minor and are thus irrelevant for all present practical applications, the theories are accepted for a given period of time and are used for prognoses regarding new 
phenomena. Eventually, these imperfect theories are replaced by newer theories that deviate less from empirical observations. Consequently, introducing the degree of empirical support for a specific theory may be more beneficial for the scientific progress as compared to plainly stating and following the common NHST's accept/reject-decision. 


\section{Experimental investigation}

In order to investigate interpretational biases of facial expressions in social anxiety, the present study assessed trustworthiness judgments towards facial stimuli. The judgment of trustworthiness can be hypothesized to entail a more directly socially relevant component, as compared to valence or arousal ratings. For example, Fenske and co-authors (Fenske, Raymond, Kessler, Westoby, \& Tipper, 2005) found that ratings of trustworthiness are associated with (induced) previous approach behavior towards the respective faces. Interestingly, bilateral amygdala damage impairs the ability to discriminate between trustworthy and untrustworthy faces in humans (Adolphs, Tranel, \& Damasio, 1998) and alters social approach behavior in primates (Amaral, 2002; Emery et al., 2001). Furthermore, ratings of facial trustworthiness of experimental partners are correlated with cooperative social behavior towards the same partners (van't Wout \& Sanfey, 2008). Finally, trustworthiness judgments reflect the detection of subtle facial features that serve as cues for approach or avoidance responses (Todorov, 2008). In summary, ratings of trustworthiness appear especially promising for an experimental investigation of associations between ratings of facial stimuli and social anxiety.

The current study was planned to test the association between ratings of socially relevant facial features and social anxiety. Specifically, ratings of attributed trustworthiness towards facial stimuli were investigated. Participants were asked to rate the perceived trustworthiness of untrustworthy, neutral, and trustworthy faces. Thus, by incorporating three distinct stimulus conditions, this design allowed for the evaluation of specific interpretation biases as found in previous research (see Table 1). 
In addition to the trustworthiness ratings of facial pictures, participants were asked to rate the same stimuli on attributed intelligence, which implied to a lesser degree social approach or avoidance behavior as compared to trustworthiness ratings. This control condition therefore enabled to explore the specificity of any finding for the perceived dimension of trustworthiness. Moreover, in contrast to the previously mentioned group studies, a correlational approach was implemented to better grasp the dimensional conceptualization and empirical understanding of social anxiety (e.g., Ruscio et al., 2008) by recruiting a sufficiently large sample of unselected undergraduate students.

Based on the current inconsistent state of research on facial expressions and selfratings in social anxiety, the classical NHST-approach of testing $H_{1}$ ("in at least one stimulus category, social anxiety influences the ratings") versus $H_{0}$ ("social anxiety does not influence the ratings in any category") may not be the appropriate strategy for analyzing data looking at this association. When merely testing the plausibility of the classical unconstrained $H_{0}$, the four previously reported response patterns (compare Table 1) remain unrecognized within this approach. However, for the present purposes, it is not the overall probability of one single $H_{0}$ that is of interest (see also Cohen, 1994). Instead, a test of the different models provides a more comprehensive and elaborate answer of how likely or unlikely a specific response pattern is for a given dataset (Klugkist, van Wesel, \& Bullens, 2011). Accordingly, the most appropriate analytic strategy is to test the four response patterns by converting them into informative hypotheses (Hoijtink, 2012), which implement the specific constraints on the parameters of interest. Consequently, a Bayesian evaluation was implemented that allowed for direct tests of the empirical support in order to compare the four informative hypotheses (Hoijtink, 2012; Kluytmans, Van De Schoot, \& Hoijtink, 2012). This new data analytic 
approach has been developed very recently and has been applied, so far, only once in the field of abnormal psychology (Vossbeck-Elsebusch \& Gerlach, 2012).

\subsection{Method}

\subsubsection{Participants}

Participants were recruited from undergraduate psychology classes at Boston University and received three hours of credit towards the Psychology 101 research participation requirement as compensation. All subjects willing to participate underwent a short initial phone screening to ensure that only individuals with normal or corrected to normal vision participated in the experiment. Only female individuals were recruited. The study was approved by the Institutional Review Board of Boston University.

Participants were screened for current psychosis and substance use with a structured clinical interview (SCID; First, Spitzer, Gibbon, \& Williams, 2002). None of the participants were found to suffer from psychotic symptoms or severe substance use which would have led to exclusion from the study. Informed consent was obtained from 101 participants who all matched the inclusion criteria. Data from three participants were missing due to equipment failure, yielding a final sample of $\mathrm{N}=98$. The subject's mean age was 18.7 years $(\mathrm{SD}=1.0)$. Regarding the ethnic background of our sample, 49 participants (50\%) identified themselves as White, 27 participants were Asian (28\%), ten participants (10\%) were Hispanic, 3

participants (3\%) were African American, and the remaining 9 subjects (9\%) identified themselves as belonging to a different ethnic group. 


\subsubsection{Questionnaires}

All participants completed a battery of the following self-report questionnaires.

Demographics Questionnaire. Participants were asked to report age, race/ethnicity, and other demographic aspects with a standard demographic questionnaire.

Beck Depression Inventory-II (BDI-II; Beck, Steer, \& Brown, 1996). The BDI-II is a 21-item measure of depression symptoms. Each question consists of four statements, and respondents selected the statement that best described the way they have been feeling over the past two weeks. The BDI-II reliably assesses depressive symptoms (Beck, Steer, Ball, \& Ranieri, 1996).

State-Trait Anxiety Inventory (STAI; Spielberger, Gorsuch, \& Lushene, 1970). The STAI is a 20-item questionnaire used to measure state and trait anxiety in adults. It is one of the most frequently used measures in applied psychology research and possesses satisfying internal reliability and validity (D. B. Clark et al., 1997). For the purposes of the experiment, only the trait anxiety scale was used.

Social Interaction Anxiety Scale (SIAS; Mattick \& Clarke, 1998). The SIAS assesses fears of more general social interaction situations. The scale has good levels of internal consistency and adequate construct validity (Brown et al., 1997).

Social Phobia and Anxiety Inventory (SPAI; Turner, Beidel, Dancu, \& Stanley, 1989). The SPAI consists of 45 items which measure the cognitive, somatic, and behavioral dimensions of social anxiety. The SPAI possesses a high test-retest reliability and internal consistency. The instrument is capable of differentiating patients with SAD from normal controls and also from other anxiety patients (Peters, 2000) and has good construct validity (Eidecker, Glöckner-Rist, \& Gerlach, 2010). 
Social Phobia Inventory (SPIN; Connor et al., 2000).The SPIN is a 17-item measure to assess symptoms of SAD and has been shown to have satisfactory psychometric properties (Antony, Coons, McCabe, Ashbaugh, \& Swinson, 2006).

\subsubsection{Facial stimuli}

The 198 computer-generated face stimuli used in the experiment were taken from a larger publicly available database created at Princeton University (http://webscript.princeton.edu/ tlab/databases/database-6-trustworthiness-dataset/). The software FaceGen 3.1 was used for generating the stimuli. All faces in this database were presented with gaze directed at the participant in front of a black background. In order to reduce possibly confounding effects of gender, race and paraphernalia, all facial stimuli were male, Caucasian, and bald. Faces were created to display three levels of trustworthiness with a procedure that is described in more detail by Oosterhof and Todorov (2008). The respective categories comprised of "not trustworthy", "neutral", and "trustworthy" facial characteristics.

The facial stimuli used in the protocol consisted of 66 different facial identities with each three degrees of trustworthiness, resulting in a total of 198 stimuli. The size of each stimulus was $400 \times 477$ pixels, resulting in a measurable size of $141.11 \times 168.27 \mathrm{~mm}$ on the computer screen. An example of one identity in its various degrees of trustworthiness is shown in Figure 2. 


\section{Figure 2}

Facial stimuli

(A)

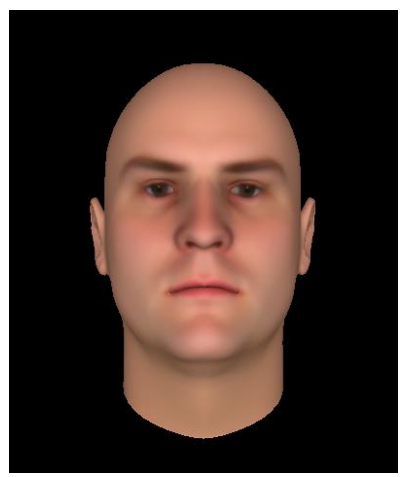

(B)

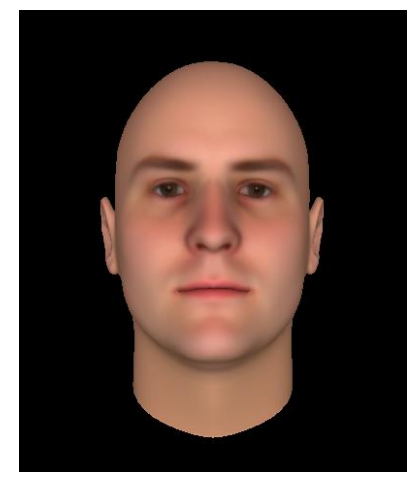

(C)

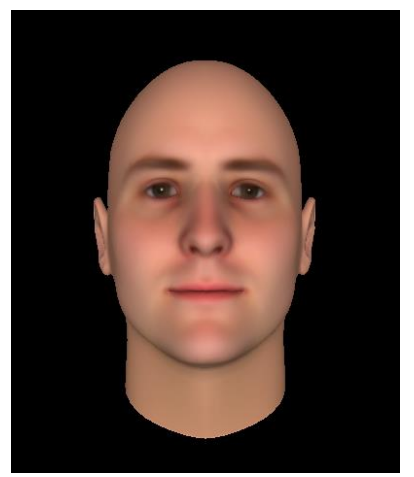

Note: (A), untrustworthy face; (B), neutral face; (C), trustworthy face.

\subsubsection{Procedure}

After obtaining informed consent, participants were seated in front of a 15 inch cathode ray tube monitor with an attached keyboard. The computerized experimental procedure was programmed with the software E-Prime ${ }^{\circledR}$ (Psychology Software Tools, Inc.; Sharpsburg, PA, USA). The experimental task began with a short training block with twelve different stimuli in order to ensure that participants gave their response as quickly as possible. For the main experiment, only ratings that were given no later than $1000 \mathrm{~ms}$ after stimulus onset were included in the analyses in order to capture the participants' immediate judgment of facial trustworthiness. Only during the training trials did subjects receive feedback about whether they were responding quickly enough. Participants were instructed to indicate their judgment of facial trustworthiness by pressing one of three buttons, 1 ("not trustworthy"), 2 ("neither trustworthy nor untrustworthy") or 3 ("trustworthy"), for each of the 198 presented stimuli. 
Additionally, a control condition was implemented in which participants were asked to rate all facial stimuli regarding attributed intelligence. The same buttons, 1 ("not intelligent"), 2 ("neither intelligent nor unintelligent"), and 3 ("intelligent"), were used in the control condition. Again, only ratings given within $1000 \mathrm{~ms}$ after stimulus onset were entered in the analyses.

Face stimuli were presented in six blocks with 66 pictures each. Conditions (trustworthiness or intelligence ratings) were randomized between blocks but fixed within each block, so that all 66 subsequently presented stimuli of a respective block had to be rated on the same dimension. Thus, participants rated facial trustworthiness in three of the blocks and facial intelligence in the other three blocks, while the order of blocks was randomized. Also, the 198 facial stimuli that had to be rated in each of the two conditions were randomly assigned to one of the three respective blocks. To reduce fatigue, participants could pause as long as they wanted before starting the next block.

Each of the 66 rating trials within a block commenced with a reminder of which attribute was to be rated. The respective condition ("Trustworthiness" or "Intelligence") was on display for $1000 \mathrm{~ms}$ with white text on a black background in the center of the screen. Following this, a white fixation cross was shown for another $1000 \mathrm{~ms}$ after which the face stimulus was displayed for $500 \mathrm{~ms}$. Subsequently, the monitor went black for $2000 \mathrm{ms,}$, after which the next trial commenced. For a graphical description of the procedure, see Figure 3. 


\section{Figure 3}

Procedure for each of the 396 rating trials.

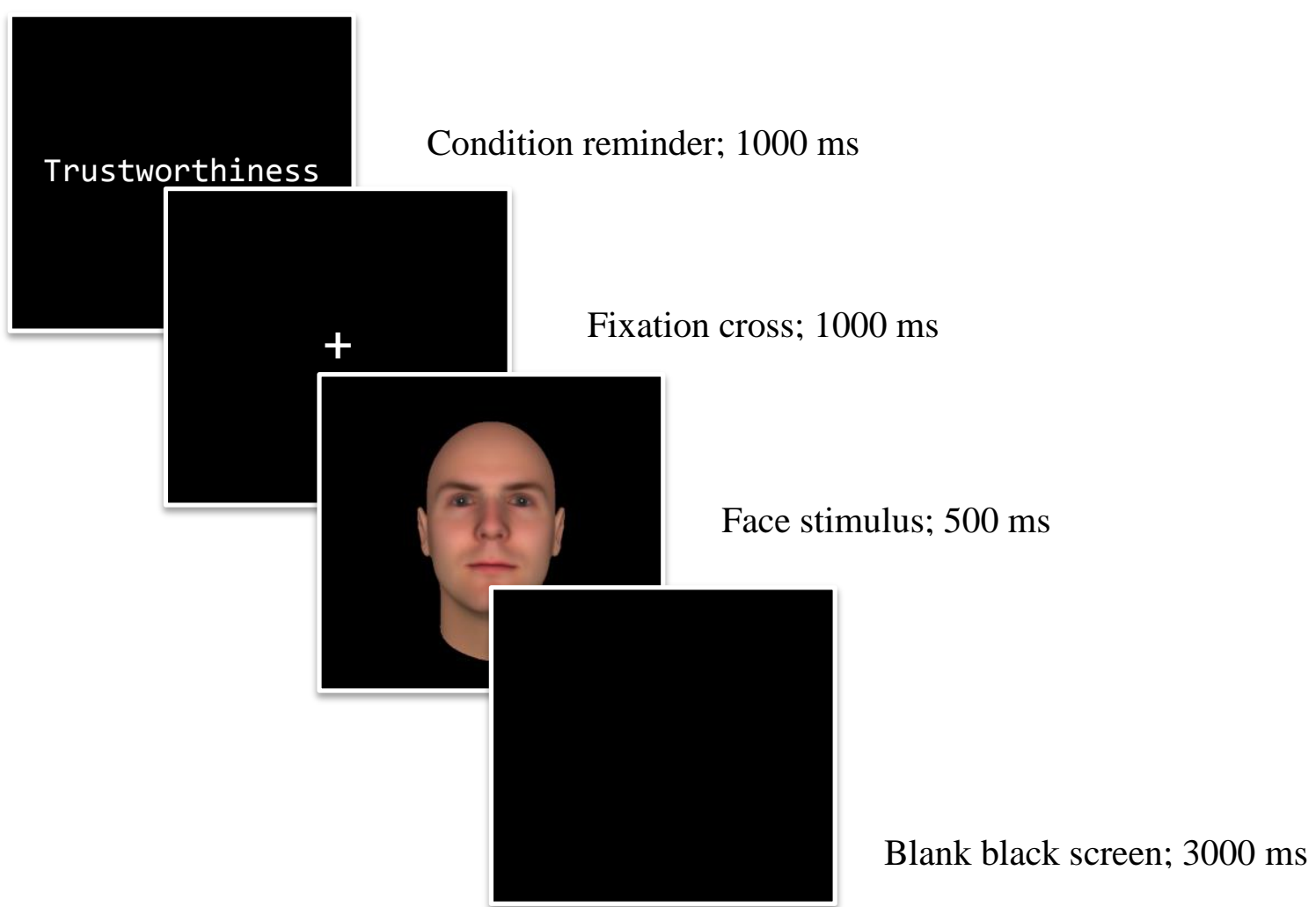

\subsubsection{Data preparation}

We first calculated the correlations between the various social anxiety questionnaires to explore the possibility of aggregating these scores into a single principal component. Correlations between the SIAS, SPAI and SPIN scores ranged between $r=.79$ and $r=.84$ and were thus sufficiently high to extract a composite score of social anxiety. We therefore conducted a Principal Component Analysis on the SIAS, SPAI and SPIN mean scores and obtained a standardized Social Anxiety (SA) score that we used in the main analyses.

Regarding the face stimuli ratings, we calculated mean scores for each facial category (untrustworthy, neutral, and trustworthy) and condition (trustworthiness and intelligence 
ratings). Therefore, six dependent variables were further analyzed for each participant: mean trustworthiness ratings for each the untrustworthy, neutral, and trustworthy faces, and mean intelligence ratings for the same face categories.

\subsubsection{Data analysis}

We analyzed the data using a Bayesian evaluation of informative hypotheses (Hoijtink, 2012) and tested four result patterns, found previously in similar studies (compare Table 1). More specifically, we first transformed the group results into correlational patterns (see also Table 4), which were then entered as models in the analyzing software, BIEMS (Mulder, Hoijtink, \& de Leeuw, 2012; Mulder, Hoijtink, \& Klugkist, 2010; Mulder et al., 2009). The model selection criterion or test statistic in this kind of analyses was the Bayes factor $(B F)$, which refers to the calculated amount of support in the data for each of the previously entered models, compared to a model without constraints on the correlations. In other words, the $B F$ is a quantification of the degree of evidence in the data in favor of each of the hypotheses of interest. Therefore, and in contrast to classical testing approaches, this does not create an index of the overall "unlikeliness" of $H_{0}$ but rather individual likelihoods of our various informative $H_{1}$ s. As noted above, although classificatory interpretations and guidelines for the size of the $B F$ are not well founded and somewhat arbitrary, there have been some suggestions for interpreting the magnitude of the effects (Jeffreys, 1961; Kass \& Raftery, 1995). For example, a $B F$ larger than three is considered to be positive evidence in favor of the model entertained. In other words, the model entertained is three times more likely than the model without constraints on the correlations.

In addition to the $B F$, we also report the posterior model probabilities $(P M P)$. These simply standardized the specific $B F$ by the sum of $B F s$, therefore allowing a direct 
comparison of the support in the data for each of the models. Accordingly, PMPs ranges between 0 (the model is unlikely) and 1 (the model is the most likely).

Regarding the stability of the obtained results, additional analyses were included. Data were simulated for four same-size samples $(\mathrm{N}=98)$ that were fitted perfectly after the restrictions of each one of the models, respectively. Subsequently, these "perfect matches" were analyzed with the same procedures as for the empirical data. Consequently, descriptive comparisons between observed and simulated $B F S$ are possible in order to estimate the stability of the results.

\subsection{Results}

Sample characteristics including means and ranges of scores for the self-report measures are listed in Table 3. 


\section{Table 3}

Sample characteristics

\begin{tabular}{lcc} 
& Range & Mean (SD) \\
\hline BDI-II & $0-33$ & $8.8(6.7)$ \\
STAI & $40-61$ & $51.5(3.5)$ \\
SIAS & $0-62$ & $21.9(14.6)$ \\
SPAI & $2-152$ & $54.7(30.9)$ \\
SPIN & $0-54$ & $16.4(11.8)$ \\
SA & $-1.5-3.1$ & $0(1.0)$ \\
\hline
\end{tabular}

Note: BDI-II, Beck Depression Inventory II; STAI, State-Trait Anxiety Inventory; SIAS, Social Anxiety Interaction Scale; SPAI, Social Phobia and Anxiety Inventory; SPIN, Social Phobia Inventory; SA, Social Anxiety principal component (see data preparation section).

The Bayesian evaluation of the model comparisons on attributed trustworthiness and social anxiety, $B F s$ and $P M P s$ are largest for Model 1, which assumes independence of social anxiety and trustworthiness ratings for all categories (see Table 4). The second best fit is found for Model 3, which assumes a negative bias of social anxiety regarding the evaluation of neutral faces. Smaller BFs and PMPs are obtained for Model 2 that assumes a more negative evaluation of specifically untrustworthy faces in social anxiety, and for Model 4, which assumes a negative bias for trustworthy faces.

For the intelligence ratings, Model 1, which assumes independence of intelligence ratings and social anxiety, yielded again the largest $B F$ and $P M P$. The second best fit was found for Model 2, that assumes a less positive rating of intelligence of untrustworthy faces in individuals with higher social anxiety scores. Models 3 and 4, which assume negative 
biases of intelligence ratings on respectively neutral or trustworthy faces, were found to have lower BFs and PMPs.

Additional analyses regarding the data simulated after each of the models' constraints can be found in Table 5. On an ordinal descriptive level, the pattern of results that best approximates the empirical data is the one simulated after Model 1.

\section{Table 4}

Model evaluation of facial ratings and social anxiety

\begin{tabular}{lcccc} 
& Model 1 & Model 2 & Model 3 & Model 4 \\
\hline Untrustworthy faces & $\mathrm{r}=0$ & $\mathrm{r}<0^{*}$ & $\mathrm{r}=0$ & $\mathrm{r}=0$ \\
Neutral faces & $\mathrm{r}=0$ & $\mathrm{r}=0$ & $\mathrm{r}<0^{*}$ & $\mathrm{r}=0$ \\
Trustworthy faces & $\mathrm{r}=0$ & $\mathrm{r}=0$ & $\mathrm{r}=0$ & $\mathrm{r}<0^{*}$ \\
\hline
\end{tabular}

DV: Trustworthiness ratings

$\begin{array}{lllll}B F & 34.79 & 7.31 & 11.69 & 5.29 \\ P M P & 0.58 & 0.12 & 0.19 & 0.09\end{array}$

DV: Intelligence ratings

$\begin{array}{lllll}B F & 35.65 & 22.05 & 4.63 & 6.56 \\ \text { PMP } & 0.51 & 0.32 & 0.07 & 0.09\end{array}$

Note: * Higher levels of social anxiety are associated with lower values on the facial ratings. $B F$, Bayes Factor; $P M P$, posterior model probability. 


\section{Table 5}

Bayes factors simulated data

\begin{tabular}{ccccc} 
& Model 1 & Model 2 & Model 3 & Model 4 \\
\hline$B F(M 1)$ & 76.47 & 18.46 & 17.92 & 19.30 \\
$B F(M 2)$ & 0.02 & 35.47 & 0.01 & 0.01 \\
$B F(M 3)$ & 0.03 & 0.01 & 40.94 & 0.01 \\
$B F(M 4)$ & 0.00 & 0.02 & 0.00 & 57.15 \\
\hline
\end{tabular}

Note: Models were simulated by assuming a moderate effect $R^{2}=.15 ; B F$, Bayes Factor; $P M P$, posterior model probability; $B F(M 1)$, Bayes Factor obtained by data simulated after Model 1.

\subsection{Discussion}

The best fitting model for the relationship of social anxiety and attributed facial trustworthiness was defined by the complete independence of self-ratings and social anxiety. According to the analysis, it is three times more likely that social anxiety does not influence trustworthiness judgments of faces than assuming any kind of negative interpretation bias being associated with social anxiety. The same result was true for attributed intelligence: the best fit was found for the independence model of social anxiety and judgments of facial intelligence. Nonetheless, for the remaining models, the fits differed between trustworthiness and intelligence ratings, indicating that, indeed, ratings of distinct characteristics were gathered instead of a more global judgment of the presented stimuli.

To give an estimation regarding the stability of the results, data were simulated according to each of the models' restrictions and analyzed the same way than the observed data to enable comparisons between the respective Bayes Factors (see Table 4 and Table 5). 
Especially the comparison between the original results and the data simulated after Model 1 is of interest: although the $B F(M 1)$ for Model 1 is almost twice as high as the $B F$ found for Model 1 in the observed data, the pattern of the four $B F(M 1)$ matches the original results best when compared to the patterns of $B F$ obtained by the remaining simulated data sets. Consequently, for the observed data, Model 1 is not a perfect fit, but it is nonetheless the most likely model having generated the empirical data, therefore indicating the stability of the empirically derived results.

The outcomes were much in line with previous results on self-ratings of facial expressions in social anxiety as presented in Table 1. Although a judgment of a more social characteristic was implemented and also the task load for the participants was minimized, the magnitude of social anxiety effects on ratings of facial expressions were minimal. This was true for both the rating dimension of trustworthiness and intelligence. The notion of hypersensitivity towards negative facial expressions in social anxiety (Lundh \& Öst, 1996; Mogg \& Bradley, 2002; Rapee \& Heimberg, 1997) presumably reflecting a general biologically prepared reaction towards threatening social cues (Öhman, 1986; Seligman, 1971) was not confirmed by the results. In addition, social anxiety did not seem to be characterized by a specific neglect of safety and cooperation cues, as was proposed by Trower and Gilbert (1989): Model 4, which specifically supported a negative bias for trustworthy faces in social anxiety, received the least amount of support in our data.

Furthermore, the findings are also consistent with the sometimes-reported differences found between participants with high and low levels of social anxiety. These models do have some empirical support in our data set and should not simply be classified as "wrong"; they are, however, less likely when compared to the independence model. This suggests that the effect size of such rating biases, if existent, may be small in size. Note, that the statistical 
power was often too low in previous studies to find small effects. Considering that positive findings are more likely to be published than findings without significant effects (file drawer problem), and based on the present results, it can be hypothesized that approximately more than twice the number of studies on emotional expressions and social anxiety were actually conducted but have never been published due to non-significant results.

Major limitations of this study relate to restrictions with regard to the generalizability of the presented results. Since participant's diagnostic status was not assessed, the findings cannot be generalized to levels of clinical social anxiety. However, the sample's score ranges on the social anxiety questionnaires indicated pathological levels of social fears in at least some participants. Regarding responses on the SIAS, Mattick and Clarke (1998), as well as Heimberg and coauthors (1992), reported a cut-off score of 34, which was exceeded by 21 participants (21.4\%). In addition, 35 subjects (35.7\%) scored above the proposed SPIN cutoff score of 19 (Connor et al., 2000), which has been used to distinguish between a clinical population of SAD and community and psychiatric communities without social fears. Even when applying a more conservative cut-off score of 25 (Ranta, Kaltiala-Heino, Rantanen, Tuomisto, \& Marttunen, 2007; Sosic, Gieler, \& Stangier, 2008), 19 participants (19.4\%) scored above this threshold.

When considering the results in the broader framework of contemporary models of social anxiety, the implications are interesting. As mentioned earlier, Rapee and Heimberg (1997) propose two parallel attentional mechanisms that generate and maintain anxiety in a given social situation. One path referred to attention allocated to external indicators of negative evaluation (such as a frowning audience), the other one comprised of an increased focus of attention towards internal cues (e.g., feeling oneself blushing). Rapee and Heimberg (1997) argue that the focus on internal cues in a feared situation would enhance state levels of 
social anxiety, whereas focusing on external cues (which are most likely less threatening than the distorted internal representations) would reduce social fears. Consequently, focusing on and further processing of internal cues and interoceptive information in contrast to external characteristics of the situation may be the more relevant mechanism in the pathology of SAD (see also D. M. Clark \& Wells, 1995; Spurr \& Stopa, 2002). The present results support this notion insofar that a biased interpretation of external characteristics was not revealed; however, the experiment was not conducted in an actual fear-relevant situation since participants were alone in the room while they worked on a clearly non-evaluative task. Nonetheless, especially when considering the intensity of the fear to show signs of anxiety in social situations (Bögels \& Reith, 1999; Fahlén, 1996), the feared visibility of somatic symptoms (Gerlach, Mourlane, \& Rist, 2004), and the efficacy of task concentration tasks and trainings in socially anxious patients and participants (Chaker, Hofmann, \& Hoyer, 2010; Woody, 1996), the investigation of attentional, cognitive, and interpretational processes regarding internal cues in social anxiety may be more promising.

Taken together, the results replicate the finding that social anxiety does not influence ratings of facial expressions and critically evaluated its likelihood in relation to other previously proposed effects of social anxiety on ratings of face stimuli. The outcome of the Bayesian analysis suggests that previous reports of biased face processing in social anxiety may have reflected more extreme (and less likely) outcomes and thus might have overestimated the size and presence of an actual effect. Consequently, for the majority of individuals suffering from social anxiety, facial expressions or other external cues in actual social situations may be less fear relevant as compared to internal cues of anxiety for the development and maintenance of social fears. 


\section{$6 \quad$ References}

Acarturk, C., de Graaf, R., van Straten, A., Have, M. T., \& Cuijpers, P. (2008). Social phobia and number of social fears, and their association with comorbidity, health-related quality of life and help seeking: a population-based study. Social Psychiatry and Psychiatric Epidemiology 43(4), 273-279.

Adolphs, R., Tranel, D., \& Damasio, A. R. (1998). The human amygdala in social judgment. Nature, 393(6684), 470-474.

Amaral, D. G. (2002). The primate amygdala and the neurobiology of social behavior: Implications for understanding social anxiety. Biological Psychiatry, 51(1), 11-17. American Psychiatric Association. (1980). Diagnostic and statistical manual of mental disorders (3 ed.). Washington, DC: American Psychiatric Association.

American Psychiatric Association. (2000). Diagnostic and Statistical Manual of Mental Disorders (4 ed.). Washington, D.C.: American Psychiatric Association.

Amir, N., Klumpp, H., Elias, J., Bedwell, J. S., Yanasak, N., \& Miller, L. S. (2005). Increased activation of the anterior Cingulate cortex during processing of disgust faces in individuals with social phobia. Biological Psychiatry, 57(9), 975-981. doi: DOI 10.1016/j.biopsych.2005.01.044

Amir, N., Najmi, S., Bomyea, J., \& Burns, M. (2010). Disgust and Anger in Social Anxiety. International Journal of Cognitive Therapy, 3(1), 3-10.

Antony, M. M., Coons, M. J., McCabe, R. E., Ashbaugh, A., \& Swinson, R. P. (2006). Psychometric properties of the social phobia inventory: Further evaluation. Behaviour Research and Therapy, 44(8), 1177-1185. doi: DOI 10.1016/j.brat.2005.08.013 
Association, A. P. (2010). Publication manual of the American Psychological Association (6 ed.). Washington, DC.

Bakan, D. (1966). Test of Significance in Psychological Research. Psychological Bulletin, 66(6), 423-\&.

Beck, A. T., Steer, R. A., Ball, R., \& Ranieri, W. F. (1996). Comparison of Beck Depression Inventories-IA and -II in psychiatric outpatients. Journal of Personality Assessment, 67(3), 588-597.

Beck, A. T., Steer, R. A., \& Brown, G. K. (1996). Manual for the Beck Depression InventoryII. San Antonio, TX: Psychological Corporation.

Bittner, A., Goodwin, R. D., Wittchen, H. U., Beesdo, K., Hofler, M., \& Lieb, R. (2004). What characteristics of primary anxiety disorders predict subsequent major depressive disorder? Journal of Clinical Psychiatry, 65(5), 618-626.

Bögels, S. M., \& Reith, W. (1999). Validity of two questionnaires to assess social fears: The Dutch Social Phobia and Anxiety Inventory and the Blushing, Trembling and Sweating Questionnaire. Journal of Psychopathology and Behavioral Assessment, 21(1), 51-66.

Bolton, J., Cox, B., Clara, I., \& Sareen, J. (2006). Use of alcohol and drugs to self-medicate anxiety disorders in a nationally representative sample. Journal of Nervous and Mental Disease, 194(11), 818-825.

Breslau, J., Aguilar-Gaxiola, S., Kendler, K. S., Su, M., Williams, D., \& Kessler, R. C. (2006). Specifying race-ethnic differences in risk for psychiatric disorder in a USA national sample. Psychological Medicine, 36(1), 57-68. 
Brown, E. J., Turovsky, J., Heimberg, R. G., Juster, H. R., Brown, T. A., \& Barlow, D. H. (1997). Validation of the social interaction anxiety scale and the social phobia scale across the anxiety disorders. Psychological Assessment, 9(1), 21-27.

Campbell, D. W., Sareen, J., Stein, M. B., Kravetsky, L. B., Paulus, M. P., Hassard, S. T., \& Reiss, J. P. (2009). Happy but Not So Approachable: The Social Judgments of Individuals with Generalized Social Phobia. Depression and Anxiety, 26(5), 419-424. doi: Doi 10.1002/Da.20474

Chaker, S., Hofmann, S. G., \& Hoyer, J. (2010). Can a one-weekend group therapy reduce fear of blushing? Results of an open trial. Anxiety, Stress \& Coping: An International Journal, 23(3), 303-318.

Chavira, D. A., \& Stein, M. B. (2005). Childhood social anxiety disorder: from understanding to treatment. Child and Adolescent Psychiatric Clinics of North America, 14(4), 797818, ix.

Chavira, D. A., Stein, M. B., Bailey, K., \& Stein, M. T. (2004). Child anxiety in primary care: prevalent but untreated. Depression and Anxiety, 20(4), 155-164.

Choy, Y., Schneier, F. R., Heimberg, R. G., Oh, K. S., \& Liebowitz, M. R. (2008). Features of the offensive subtype of Taijin-Kyofu-Sho in US and Korean patients with DSMIV social anxiety disorder. Depression and Anxiety, 25(3), 230-240.

Chronis-Tuscano, A., Degnan, K. A., Pine, D. S., Perez-Edgar, K., Henderson, H. A., Diaz, Y., .. . Fox, N. A. (2009). Stable Early Maternal Report of Behavioral Inhibition Predicts Lifetime Social Anxiety Disorder in Adolescence. Journal of the American Academy of Child and Adolescent Psychiatry, 48(9), 928-935. 
Clark, D. B., Feske, U., Masia, C. L., Spaulding, S. A., Brown, C., Mammen, O., \& Shear, M. K. (1997). Systematic assessment of social phobia in clinical practice. [Review]. Depression and Anxiety, 6(2), 47-61.

Clark, D. M., \& McManus, F. (2002). Information processing in social phobia. Biological Psychiatry, 51(1), 92-100.

Clark, D. M., \& Wells, A. (1995). A cognitive model of social phobia. In R. G. Heimberg, M. R. Liebowitz, D. A. Hope \& F. R. Schneier (Eds.), Social phobia: diagnosis, assessment, and treatment. New York, London: The Guilford Press.

Cohen, J. (1994). The Earth Is Round ( < .05). American Psychologist, 49(12), 997-1003.

Coles, M. E., \& Heimberg, R. G. (2005). Recognition bias for critical faces in social phobia: a replication and extension. Behaviour Research and Therapy, 43(1), 109-120. doi: DOI 10.1016/j.brat.2003.12.001

Connor, K. M., Davidson, J. R. T., Churchill, L. E., Sherwood, A., Foa, E., \& Weisler, R. H. (2000). Psychometric properties of the Social Phobia Inventory (SPIN) - New selfrating scale. British Journal of Psychiatry, 176, 379-386.

Cooper, R. (2012). Original thought. Retrieved 7/25/2012, from Own Brain.

Davidson, J. R., Hughes, D. L., George, L. K., \& Blazer, D. G. (1993). The epidemiology of social phobia: findings from the Duke Epidemiological Catchment Area Study. Psychological Medicine, 23(3), 709-718.

de Jong, P. J., Merckelbach, H., Bogels, S., \& Kindt, M. (1998). Illusory correlation and social anxiety. Behaviour Research and Therapy, 36(11), 1063-1073.

De Santis, F. (2004). Statistical evidence and sample size determination for Bayesian hypothesis testing. Journal of Statistical Planning and Inference, 124(1), 121-144. doi: Doi 10.1016/S0378-3758(03)00198-8 
Dimberg, U. (1997). Social fear and expressive reactions to social stimuli. Scandinavian Journal of Psychology, 38(3), 171-174.

Dimberg, U., \& Christmanson, L. (1991). Facial Reactions to Facial Expressions in Subjects High and Low in Public Speaking Fear. Scandinavian Journal of Psychology, 32(3), 246-253.

Dimberg, U., \& Thunberg, M. (2007). Speech anxiety and rapid emotional reactions to angry and happy facial expressions. Scandinavian Journal of Psychology, 48(4), 321-328. doi: DOI 10.1111/j.1467-9450.2007.00586.x

Dyson, F. W., Eddington, A. S., \& Davidson, C. (1920). A Determination of the Deflection of Light by the Sun's Gravitational Field, from Observations Made at the Total Eclipse of May 29, 1919. Philosophical Transactions of the Royal Society of London. Series A, Containing Papers of a Mathematical or Physical Character, 220, 291-333.

Eidecker, J., Glöckner-Rist, A., \& Gerlach, A. L. (2010). Dimensional structure of the Social Interaction Anxiety Scale according to the analysis of data obtained with a German version. Journal of Anxiety Disorders, 24(6), 596-605. doi: DOI 10.1016/j.janxdis.2010.03.020

Einstein, A. (1911). Einfluss der Schwerkraft auf die Ausbreitung des Lichtes. Annalen der Physik, 35(1911), 898-908.

Einstein, A. (1916). Die Grundlage der allgemeinen Relativitätstheorie. Annalen der Physik, 49, 769-822.

Ekman, P., \& Friesen, W. V. (1971). Constants across Cultures in Face and Emotion. Journal of Personality and Social Psychology, 17(2), 124-\&.

Ekman, P., \& Friesen, W. V. (1976). Pictures of facial affect. Palo Alto, CA: Consulting Psychologists Press. 
Emery, N. J., Capitanio, J. P., Mason, W. A., Machado, C. J., Mendoza, S. P., \& Amaral, D. G. (2001). The effects of bilateral lesions of the amygdala on dyadic social interactions in rhesus monkeys (Macaca mulatta). Behavioral Neuroscience, 115(3), $515-544$.

Evans, K. C., Wright, C. I., Wedig, M. M., Gold, A. L., Pollack, M. H., \& Rauch, S. L. (2008). A functional MRI study of amygdala responses to angry schematic faces in social anxiety disorder. Depression and Anxiety, 25(6), 496-505. doi: Doi 10.1002/Da.20347

Fahlén, T. (1996). Core symptom pattern of social phobia. Depression and Anxiety, 4(5), 223-232.

Fenske, M. J., Raymond, J. E., Kessler, K., Westoby, N., \& Tipper, S. P. (2005). Attentional inhibition has social-emotional consequences for unfamiliar faces. Psychological Science, 16(10), 753-758.

First, M. B., Spitzer, R. L., Gibbon, M., \& Williams, J. B. W. (2002). Structured Clinical Interview for DSM-IV-TR Axis I Disorders, Research Version, Patient Edition With Psychotic Screen (SCID-I/P W/ PSY SCREEN). New York: Biometrics Research, New York State Psychiatric Institute.

Foa, E. B., Franklin, M. E., Perry, K. J., \& Herbert, J. D. (1996). Cognitive biases in generalized social phobia. Journal of Abnormal Psychology, 105(3), 433-439.

Furmark, T. (2002). Social phobia: overview of community surveys. Acta Psychiatrica Scandinavica, 105(2), 84-93.

Furmark, T., Henningsson, S., Appel, L., Ahs, F., Linnman, C., Pissiota, A., . . Fredrikson, M. (2009). Genotype over-diagnosis in amygdala responsiveness: affective processing in social anxiety disorder. Journal of Psychiatry \& Neuroscience, 34(1), 30-40. 
Furmark, T., Tillfors, M., Everz, P., Marteinsdottir, I., Gefvert, O., \& Fredrikson, M. (1999). Social phobia in the general population: prevalence and sociodemographic profile. Social Psychiatry and Psychiatric Epidemiology, 34(8), 416-424.

Fyer, A. J., Mannuzza, S., Chapman, T. F., Liebowitz, M. R., \& Klein, D. F. (1993). A Direct Interview Family Study of Social Phobia. Archives of General Psychiatry, 50(4), 286293.

Fyer, A. J., Mannuzza, S., Chapman, T. F., Martin, L. Y., \& Klein, D. F. (1995). Specificity in Familial Aggregation of Phobic Disorders. Archives of General Psychiatry, 52(7), 564-573.

Garcia-Donato, G., \& Chen, M. H. (2005). Calibrating Bayes factor under prior predictive distributions. Statistica Sinica, 15(2), 359-380.

Gerlach, A. L. (2005). Angst vor körperlichen Symptomen im Rahmen der Sozialen Angststörung: Ursachen und Behandlung. In N. Vriends \& J. Margraf (Eds.), Soziale Kompetenz, Sozilae Unsicherheit, Soziale Phobie: Verstehen und Verändern (3 ed.). Baltmannsweiler: Schneider Verlag Hohengehren.

Gerlach, A. L., Mourlane, D., \& Rist, F. (2004). Public and Private Heart Rate Feedback in Social Phobia: A Manipulation of Anxiety Visibility. Cognitive Behaviour Therapy, $33(1), 36-45$.

Goldin, P. R., Manber, T., Hakimi, S., Canli, T., \& Gross, J. J. (2009). Neural Bases of Social Anxiety Disorder: Emotional Reactivity and Cognitive Regulation During Social and Physical Threat. Archives of General Psychiatry, 66(2), 170-180.

Grant, B. F., Hasin, D. S., Blanco, C., Stinson, F. S., Chou, S. P., Goldstein, R. B., . . Huang, B. (2005). The epidemiology of social anxiety disorder in the United States: 
results from the National Epidemiologic Survey on Alcohol and Related Conditions. Journal of Clinical Psychiatry, 66(11), 1351-1361.

Heimberg, R. G., Mueller, G. P., Holt, C. S., Hope, D. A., \& Liebowitz, M. R. (1992). Assessment of Anxiety in Social-Interaction and Being Observed by Others - the Social-Interaction Anxiety Scale and the Social Phobia Scale. Behavior Therapy, 23(1), 53-73.

Heinrichs, N., \& Hofmann, S. G. (2001). Information processing in social phobia: A critical review. Clinical Psychology Review, 21(5), 751-770.

Heuer, K., Rinck, M., \& Becker, E. S. (2007). Avoidance of emotional facial expressions in social anxiety: The Approach-Avoidance Task. Behaviour Research and Therapy, 45(12), 2990-3001. doi: DOI 10.1016/j.brat.2007.08.010

Hofmann, S. G. (2000). Treatment of social phobia: Potential mediators and moderators. Clinical Psychology-Science and Practice, 7(1), 3-16.

Hofmann, S. G., Ehlers, A., \& Roth, W. T. (1995). Conditioning Theory - a Model for the Etiology of Public Speaking Anxiety. Behaviour Research and Therapy, 33(5), 567571.

Hofmann, S. G., Moscovitch, D. A., Kim, H. J., \& Taylor, A. N. (2004). Changes in selfperception during treatment of social phobia. Journal of Consulting and Clinical Psychology, 72(4), 588-596. doi: Doi 10.1037/0022-0006x.72.4.588

Hoijtink, H. (2012). Informative Hypotheses: Theory and Practice for Behavioral and Social Scientists. Boca Raton, FL: CRC Press, Taylor \& Francis Group.

Hwu, H. G., Yeh, E. K., \& Chang, L. Y. (1989). Prevalence of psychiatric disorders in Taiwan defined by the Chinese Diagnostic Interview Schedule. Acta Psychiatrica Scandinavica, 79(2), 136-147. 
Jeffreys, H. (1935). Some Tests of Significance, Treated by the Therory of Probability. Proceedings of the Cambridge Philosophy Society, 31, 203-222.

Jeffreys, H. (1961). Theory of Probability (3 ed.). Oxford: Oxford University Press.

Kass, R. E., \& Raftery, A. E. (1995). Bayes Factors. Journal of the American Statistical Association, 90(430), 773-795.

Kelley, K., \& Preacher, K. J. (2012). On Effect Size. Psychological Methods, 17(2), 137-152. doi: Doi 10.1037/A0028086

Kendler, K. S., Neale, M. C., Kessler, R. C., Heath, A. C., \& Eaves, L. J. (1992). The Genetic Epidemiology of Phobias in Women - the Interrelationship of Agoraphobia, Social Phobia, Situational Phobia, and Simple Phobia. Archives of General Psychiatry, 49(4), 273-281.

Kessler, R. C., Berglund, P., Demler, O., Jin, R., Merikangas, K. R., \& Walters, E. E. (2005a). Lifetime prevalence and age-of-onset distributions of DSM-IV disorders in the National Comorbidity Survey Replication. Archives of General Psychiatry, 62(6), 593-602.

Kessler, R. C., Chiu, W. T., Demler, O., Merikangas, K. R., \& Walters, E. E. (2005b). Prevalence, severity, and comorbidity of 12-month DSM-IV disorders in the National Comorbidity Survey Replication. Archives of General Psychiatry, 62(6), 617-627.

Kessler, R. C., McGonagle, K. A., Zhao, S., Nelson, C. B., Hughes, M., Eshleman, S., . . Kendler, K. S. (1994). Lifetime and 12-month prevalence of DSM-III-R psychiatric disorders in the United States. Results from the National Comorbidity Survey. Archives of General Psychiatry, 51(1), 8-19. 
Kleinknecht, R. A., Dinnel, D. L., Kleinknecht, E. E., Natsuki, H. M. S., \& Harada, N. B. A. (1997). Cultural factors in social anxiety: a comparison of social phobia symptoms and Taijin kyofusho. Journal of Anxiety Disorders, 11(2), 157-177.

Klugkist, I., van Wesel, F., \& Bullens, J. (2011). Do we know what we test and do we test what we want to know? International Journal of Behavioral Development, 35(6), 550-560. doi: Doi 10.1177/0165025411425873

Kluytmans, A., Van De Schoot, R., \& Hoijtink, H. (2012). Illustrating Bayesian evaluation of informative hypotheses for regression models. [Methods]. Frontiers in Psychology, 3. doi: 10.3389/fpsyg.2012.00002

Lange, W. G., Heuer, K., Langner, O., Keijsers, G. P. J., Becker, E. S., \& Rinck, M. (2011). Face value: Eye movements and the evaluation of facial crowds in social anxiety. Journal of Behavior Therapy and Experimental Psychiatry, 42(3), 355-363. doi: DOI 10.1016/j.jbtep.2011.02.007

Lange, W. G., Keijsers, G., Becker, E. S., \& Rinck, M. (2008). Social anxiety and evaluation of social crowds: Explicit and implicit measures. Behaviour Research and Therapy, 46(8), 932-943. doi: DOI 10.1016/j.brat.2008.04.008

Lee, C. K., Kwak, Y. S., Yamamoto, J., Rhee, H., Kim, Y. S., Han, J. H., . . Lee, Y. H. (1990). Psychiatric epidemiology in Korea. Part II: Urban and rural differences. Journal of Nervous and Mental Disease, 178(4), 247-252.

Lissek, S., Levenson, J., Biggs, A. L., Johnson, L. L., Arneli, R., Pine, D. S., \& Grillon, C. (2008). Elevated fear conditioning to socially relevant unconditioned stimuli in social anxiety disorder. American Journal of Psychiatry, 165(1), 124-132.

Lundh, L. G., \& Öst, L. G. (1996). Recognition bias for critical faces in social phobics. Behaviour Research and Therapy, 34(10), 787-794. 
Lundqvist, D., Flykt, A., \& Öhman, A. (1998). The karolinska directed emotional faces KDEF: CD-ROM from Department of Clinical Neuroscience, Psychology section, Karolinska Institute.

Lykken, D. T. (1968). Statistical Significance in Psychological Research. Psychological Bulletin, 70(3p1), 151-\&.

Mancini, C., VanAmeringen, M., Szatmari, P., Fugere, C., \& Boyle, M. (1996). A high-risk pilot study of the children of adults with social phobia. Journal of the American Academy of Child and Adolescent Psychiatry, 35(11), 1511-1517.

Marks, I. M., \& Gelder, M. G. (1966). Different ages of onset in varieties of phobia. American Journal of Psychiatry, 123(2), 218-221.

Markus, H. R., \& Kitayama, S. (1991). Culture and the self: Implications for cognition, emotion, and motivation. Psychological Review, 98, 224-253.

Matsumoto, D., \& Ekman, P. (1988). Japanese and caucasian facial expressions of emotion and neutral faces. San Francisco, CA: San Francisco State University.

Mattick, R. P., \& Clarke, J. C. (1998). Development and validation of measures of social phobia scrutiny fear and social interaction anxiety. Behaviour Research and Therapy, $36(4), 455-470$.

Meehl, P. E. (1967). Theory-Testing in Psychology and Physics - Methodological Paradox. Philosophy of Science, 34(2), 103-115.

Meehl, P. E. (1990). Why Summaries of Research on Psychological Theories Are Often Uninterpretable. Psychological Reports, 66(1), 195-244.

Mellings, T. M. B., \& Alden, L. E. (2000). Cognitive processes in social anxiety: the effects of self-focus, rumination and anticipatory processing. Behaviour Research and Therapy, 38(3), 243-257. 
Merckelbach, H., Vanhout, W., Vandenhout, M. A., \& Mersch, P. P. (1989). Psychophysiological and Subjective Reactions of Social Phobics and Normals to Facial Stimuli. Behaviour Research and Therapy, 27(3), 289-294.

Mogg, K., \& Bradley, B. P. (2002). Selective orienting of attention to masked threat faces in social anxiety. Behaviour Research and Therapy, 40(12), 1403-1414.

Moitra, E., Beard, C., Weisberg, R. B., \& Keller, M. B. (2011). Occupational impairment and social anxiety disorder in a sample of primary care patients. Journal of Affective Disorders, 130(1-2), 209-212. doi: 10.1016/j.jad.2010.09.024

Moutier, C. Y., \& Stein, M. B. (1999). The history, epidemiology, and differential diagnosis of social anxiety disorder. Journal of Clinical Psychiatry, 60 Suppl 9, 4-8.

Mühlberger, A., Wieser, M. J., Herrmann, M. J., Weyers, P., Troger, C., \& Pauli, P. (2009). Early cortical processing of natural and artificial emotional faces differs between lower and higher socially anxious persons. Journal of Neural Transmission, 116(6), 735-746. doi: DOI 10.1007/s00702-008-0108-6

Mulder, J., Hoijtink, H., \& de Leeuw, C. (2012). BIEMS: A Fortran 90 Program for Calculating Bayes Factors for Inequality and Equality Constrained Models. Journal of Statistical Software, 46(2), 1-39.

Mulder, J., Hoijtink, H., \& Klugkist, I. (2010). Equality and inequality constrained multivariate linear models: Objective model selection using constrained posterior priors. Journal of Statistical Planning and Inference, 140(4), 887-906. doi: DOI 10.1016/j.jspi.2009.09.022

Mulder, J., Klugkist, I., van de Schoot, R., Meeus, W. H. J., Selfhout, M., \& Hoijtink, H. (2009). Bayesian model selection of informative hypotheses for repeated 
measurements. Journal of Mathematical Psychology, 53(6), 530-546. doi: DOI 10.1016/j.jmp.2009.09.003

Mulkens, S., de Jong, P. J., Dobbelaar, A., \& Bögels, S. M. (1999). Fear of blushing: fearful preoccupation irrespective of facial coloration. Behaviour Research and Therapy, $37(11), 1119-1128$.

Nisbett, R. E., Peng, K., Choi, I., \& Norenzayan, A. (2001). Culture and systems of thought: holistic versus analytic cognition. Psychological Review, 108(2), 291-310.

Offord, D. R., Boyle, M. H., Campbell, D., Goering, P., Lin, E., Wong, M., \& Racine, Y. A. (1996). One-year prevalence of psychiatric disorder in Ontarians 15 to 64 years of age. Canadian Journal of Psychiatry, 41(9), 559-563.

Öhman, A. (1986). Face the Beast and Fear the Face - Animal and Social Fears as Prototypes for Evolutionary Analyses of Emotion. Psychophysiology, 23(2), 123-145.

Öhman, A., \& Dimberg, U. (1978). Facial Expressions as Conditioned Stimuli for Electrodermal Responses - Case of Preparedness. Journal of Personality and Social Psychology, 36(11), 1251-1258.

Öhman, A., Dimberg, U., \& Öst, L. G. (1985). Animal and social phobias: Biological constraints on the learned fear response. In S. Reiss \& R. Bootzin (Eds.), Theoretical issues in behavior therapy (pp. 123-175). New York: Academic Press.

Okazaki, S. (1997). Sources of ethnic differences between Asian American and White American college students on measures of depression and social anxiety. Journal of Abnormal Psychology, 106, 52-60.

Oosterhof, N. N., \& Todorov, A. (2008). The functional basis of face evaluation. Proceedings of the National Academy of Sciences of the United States of America, 105(32), 1108711092. doi: DOI 10.1073/pnas.0805664105 
Öst, L. G., \& Hugdahl, K. (1981). Acquisition of Phobias and Anxiety Response Patterns in Clinical Patients. Behaviour Research and Therapy, 19(5), 439-447.

Papageorgiou, C., \& Wells, A. (2002). Effects of heart rate information on anxiety, perspective taking, and performance in high and low social-evaluative anxiety. Behavior Therapy, 33(2), 181-199.

Patterson, M. L. (1999). The evolution of a parallel process model of non-verbal communication. In P. Philippot, R. S. Feldman \& E. J. Coats (Eds.), Nonverbal behavior in social context (pp. 317-347). New York: Cambridge University Press.

Peters, L. (2000). Discriminant validity of the Social Phobia and Anxiety Inventory (SPAI), the Social Phobia Scale (SPS) and the Social Interaction Anxiety Scale (SIAS). Behaviour Research and Therapy, 38(9), 943-950.

Popper, K. R. (1935). Logik der Forschung. Wien.

Ranta, K., Kaltiala-Heino, R., Rantanen, P., Tuomisto, M. T., \& Marttunen, M. (2007). Screening social phobia in adolescents from general population: The validity of the Social Phobia Inventory (SPIN) against a clinical interview. European Psychiatry, 22(4), 244-251. doi: DOI 10.1016/j.eurpsy.2006.12.002

Rapee, R. M., \& Heimberg, R. G. (1997). A cognitive-behavioral model of anxiety in social phobia. Behaviour Research and Therapy, 35(8), 741-756.

Rosenthal, R., Rosnow, R., \& Rubin, D. (2000). Contrasts and effect sizes in behavioral research: A correlational approach. Cambridge, UK: Cambridge University Press. Rosnow, R. L., \& Rosenthal, R. (1989). Statistical Procedures and the Justification of Knowledge in Psychological Science. American Psychologist, 44(10), 1276-1284. 
Ruscio, A. M., Brown, T. A., Chiu, W. T., Sareen, J., Stein, M. B., \& Kessler, R. C. (2008). Social fears and social phobia in the USA: results from the National Comorbidity Survey Replication. Psychological Medicine, 38(1), 15-28.

Schofield, C. A., Coles, M. E., \& Gibb, B. E. (2007). Social anxiety and interpretation biases for facial displays of emotion: Emotion detection and ratings of social cost. Behaviour Research and Therapy, 45(12), 2950-2963. doi: DOI 10.1016/j.brat.2007.08.006

Seligman, M. E. (1971). Phobias and Preparedness. Behavior Therapy, 2(3), 307-320.

Sosic, Z., Gieler, U., \& Stangier, U. (2008). Screening for social phobia in medical in- and outpatients with the German version of the Social Phobia Inventory (SPIN). Journal of Anxiety Disorders, 22(5), 849-859. doi: DOI 10.1016/j.janxdis.2007.08.011

Spielberger, C. D., Gorsuch, R. L., \& Lushene, R. E. (1970). State-Trait Anxiety Inventory. Palo Alto, CA: Consulting Psychologists Press.

Spurr, J. M., \& Stopa, L. (2002). Self-focused attention in social phobia and social anxiety. Clinical Psychology Review, 22(7), 947-975.

Staugaard, S. R. (2010). Threatening faces and social anxiety: A literature review. Clinical Psychology Review, 30(6), 669-690. doi: DOI 10.1016/j.cpr.2010.05.001

Stein, M. B., Goldin, P. R., Sareen, J., Zorrilla, L. T. E., \& Brown, G. G. (2002). Increased amygdala activation to angry and contemptuous faces in generalized social phobia. Archives of General Psychiatry, 59(11), 1027-1034.

Stein, M. B., \& Kean, Y. M. (2000). Disability and quality of life in social phobia: epidemiologic findings. American Journal of Psychiatry, 157(10), 1606-1613.

Stemberger, R. T., Turner, S. M., Beidel, D. C., \& Calhoun, K. S. (1995). Social phobia: An analysis of possible developmental factors. Journal of Abnormal Psychology, 104(3), 526-531. 
Stevens, S., Gerlach, A. L., \& Rist, F. (2008). Effects of alcohol on ratings of emotional facial expressions in social phobics. Journal of Anxiety Disorders, 22(6), 940-948. doi: 10.1016/j.janxdis.2007.09.007

Straube, T., Kolassa, I. T., Glauer, M., Mentzel, H. J., \& Miltner, W. H. R. (2004). Effect of task conditions on brain responses to threatening faces in social phobics: An eventrelated functional magnetic resonance Imaging study. Biological Psychiatry, 56(12), 921-930. doi: DOI 10.1016/j.biopsych.2004.09.024

Straube, T., Mentzel, H. J., \& Miltner, W. H. R. (2005). Common and distinct brain activation to threat and safety signals in social phobia. Neuropsychobiology, 52(3), 163-168. doi: Doi 10.1159/000087987

Takahashi, T. (1989). Social phobia syndrome in Japan. Comprehensive Psychiatry, 30, 4552.

Todorov, A. (2008). Evaluating faces on trustworthiness - An extension of systems for recognition of emotions signaling approach/avoidance behaviors. Year in Cognitive Neuroscience 2008, 1124, 208-224. doi: DOI 10.1196/annals.1440.012

Trower, P., \& Gilbert, P. (1989). New Theoretical Conceptions of Social Anxiety and Social Phobia. Clinical Psychology Review, 9(1), 19-35.

Tukey, J. W. (1969). Analyzing Data - Sanctification or Detective Work. American Psychologist, 24(2), 83-\&.

Turner, S. M., Beidel, D. C., Dancu, C. V., \& Stanley, M. A. (1989). An empirically derived inventory to measure social fears and anxiety: The Social Phobia and Anxiety Inventory. Psychological Assessment: A Journal of Consulting and Clinical Psychology, 1(1), 35-40. 
van't Wout, M., \& Sanfey, A. G. (2008). Friend or foe: The effect of implicit trustworthiness judgments in social decision-making. Cognition, 108(3), 796-803. doi: DOI 10.1016/j.cognition.2008.07.002

van de Schoot, R., Mulder, J., Hoijtink, H., Van Aken, M. A. G., Dubas, J. S., de Castro, B. O., . . Romeijn, J.-W. (2011). An introduction to Bayesian model selection for evaluating informative hypotheses. European Journal of Developmental Psychology, 8(6), 713-729. doi: 10.1080/17405629.2011.621799

Vossbeck-Elsebusch, A. N., \& Gerlach, A. L. (2012). The relation between disgustsensitivity, blood-injection-injury fears and vasovagal symptoms in blood donors: Disgust sensitivity cannot explain fainting or blood donation-related symptoms. Journal of Behavior Therapy and Experimental Psychiatry, 43(1), 607-613. doi: DOI 10.1016/j.jbtep.2011.08.005

Vrana, S. R., \& Gross, D. (2004). Reactions to facial expressions: effects of social context and speech anxiety on responses to neutral, anger, and joy expressions. Biological Psychology, 66(1), 63-78. doi: DOI 10.1016/j.biopsycho.2003.07.004

Wieser, M. J., McTeague, L. M., \& Keil, A. (2011). Sustained Preferential Processing of Social Threat Cues: Bias without Competition? Journal of Cognitive Neuroscience, 23(8), 1973-1986.

Wieser, M. J., Pauli, P., Weyers, P., Alpers, G. W., \& Mühlberger, A. (2009). Fear of negative evaluation and the hypervigilance-avoidance hypothesis: an eye-tracking study. Journal of Neural Transmission, 116(6), 717-723. doi: DOI 10.1007/s00702008-0101-0 
Wittchen, H.-U., \& Fehm, L. (2001). Epidemiology, patterns of comorbidity, and associated disabilities of social phobia. Psychiatric Clinics of North America, 24(4), 617-641. doi: $10.1016 / \mathrm{s} 0193-953 \times(05) 70254-9$

Wittgenstein, L. (1921). Logisch-philosophische Abhandlung. In W. Ostwald (Ed.), Annalen der Naturphilosophie (Vol. 14).

Woody, S. R. (1996). Effects of focus of attention on anxiety levels and social performance of individuals with social phobia. Journal of Abnormal Psychology, 105(1), 61-69.

Yoon, K. L., \& Zinbarg, R. E. (2007). Threat is in the eye of the beholder: Social anxiety and the interpretation of ambiguous facial expressions. Behaviour Research and Therapy, 45(4), 839-847. doi: DOI 10.1016/j.brat.2006.05.004

Zimmermann, P., Wittchen, H. U., Hofler, M., Pfister, H., Kessler, R. C., \& Lieb, R. (2003). Primary anxiety disorders and the development of subsequent alcohol use disorders: a 4-year community study of adolescents and young adults. Psychological Medicine, 33(7), 1211-1222. 


\section{$7 \quad$ List of Figures}

Figure 1. Vicious circle of social anxiety.................................................... p. 14

Figure 2. Facial stimuli....................................................................... p. 48

Figure 3. Procedure for each of the 396 rating trials.................................... p. 50 


\section{$8 \quad$ List of Tables}

Table 1. Ratings of facial expressions............................................................ p. p. 20

Table 2. Interpretation guidelines for Bayes Factors................................... p. p. 41

Table 3. Sample characteristics........................................................................ p. p. 53

Table 4. Model evaluation of facial ratings and soical anxiety........................ p. 54

Table 5. Bayes factors for simulated data.................................................... p. 55 


\section{Appendices}

Recruitement flyer

Informed Consent

Structured Clinician Interview for DSM (SCID; parts B/C, E.1 and E.9/10)

Demographics Questionnare

Beck Depression Inventory-II (BDI-II)

State-Trait Anxiety Inventory (STAI)

Social Interaction Anxiety Scale (SIAS)

Social Phobia and Anxiety Inventory (SPAI)

Social Phobia Inventory (SPIN) 
Looking for Participants (Prof. Hofmann's Lab):

\section{Face Perception Study}

Are you female and at least 18 years old? - Then you are invited to participate in a study combining physiological and behavioral aspects of face perception using various computer-based tasks. We will measure your responses to face stimuli presented on a computer screen and measure your skin conductance during different experimental conditions.

You will receive 3 hours worth of credit towards your Psych 101 course research participation requirement.

If you are interested in participating, please send an email to emotion.perception@gmail.com to schedule an appointment.

Thank you! 


\section{-}

\section{BOSTON UNIVERSITY}

\section{Informed Consent}

Physiological indices and self-reports of facial trustworthiness judgments in high and low socially anxious subjects

\section{Purpose:}

You are asked to join a research study on the judgment of facial trustworthiness because you are a woman over the age of 18. The reason for this study is to assess the effects of specific facial features on your attribution of trustworthiness and intelligence to computer-presented faces. Furthermore, an additional goal of this study is to see whether relative levels of oxytocin or use of hormone-based birth control ("the Pill") has any influence on your perception of trustworthiness and intelligence in a series of pictures of men.

The investigation will take approximately 3 hours, for which you will receive course credit. The study will be conducted at the Center for Anxiety and Related Disorders, 648 Beacon Street, Boston, MA 02215.

\section{Procedures:}

By signing this document, you are indicating that you understand that the current study will involve three experimental tasks. You are also asked to undergo a brief psychological interview (approximately 10 minutes) prior to the experimental tasks.

During the first experimental task, you are asked to wear two sensors on one of your hand's inner surfaces to record your skin conductance in response to the face stimuli. After the sensors are attached, you are asked to just sit in a chair for 2 minutes. Afterwards, you are asked to watch pictures of 15 computer-generated faces on a computer screen and provide ratings about how trustworthy you think the respective person is. These face images will be separated by longer periods in which you will see only meaningless patterns. The experimenter will remove the sensors from your hand subsequently. The first experimental task, including attachment and detachment from the electrodes, will take approximately 35 minutes.

During the second experimental task, you are asked to watch and rate 200 computer-generated faces, which will be presented more rapidly this time. You are asked to rate how trustworthy and also how intelligent you think the respective person is. During the second task, you will not wear any sensors. After every 50 faces you rated, you will have a break from the task. You can decide on your own how long the break will be. The second experimental task will take about 40 minutes.

During the third experimental task, you are asked to complete several questionnaires. This task will take 90 minutes at the most. 
In the event that medical or psychological assistance is required, help is readily available by calling Stefan G. Hofmann, Ph.D. at the Center for Anxiety and Related Disorders (617) 3539610. This number will be answered directly during weekdays from 8 a.m. to 8 p.m. After hours there will be an answering machine that will be checked frequently.

In the event that injury occurs as a result of the research procedures, medical treatment will be available at the Center for Anxiety and Related Disorders at Boston University or, if you are a BU student, at the Boston University Student Health Service (881 Commonwealth Avenue). However, no special provision will be made for compensation or for payment for treatment solely because of your participation in this experiment. This paragraph is a statement of Boston University's policy and does not waive any of your legal rights.

Duration

The experiment will take 3 hours at the most.

Cost

There are no costs to you for participating in this study.

\section{Potential Benefits}

There are no direct benefits for the participation in this experiment. However, participation in this experiment can be of educational value for you. In addition, the results of this study may help other people in the future by increasing scientific knowledge.

\section{Risks and Discomforts}

You might experience some boredom during conducting the experimental tasks. You may also experience some discomfort when completing the questionnaires and when conducting the psychological interview. Also, you might experience some discomfort and minor skin irritation while you are wearing the physiological sensors on your hand. However, any discomfort is likely to end after finishing the investigation. Also, you are able to stop participation at any time you wish. To minimize skin irritation, you will be provided with a cleaning solution and a body lotion to treat your skin after removing the electrodes.

In order to minimize the risks, a member of the research staff will attend the experiment. After the session, he/she will be available to talk with you about any discomfort you may experience while participating. You are also able to stop participation at any time you wish.

\section{Confidentiality}

All of your responses to the tasks, questionnaires, and interviews will be anonymous, and your name will not appear in any of the results. No individual responses will be reported in any publication, only group findings will be reported. All data, identified only by subject code number, will be stored in a locked file cabinet at the Center for Anxiety and Related Disorders at Boston University. Your participation in this project will remain strictly confidential to the extent allowed by law. All data, including the audiotapes that are collected as part of this study, will be destroyed within 5 years after study completion.

\section{Contact Information}

If you have any questions regarding the research or your participation in it, either now or any time in the future, please feel free to ask them. The research team, particularly Ruth Hueweler, who may be reached at (617) 353-9610, will be happy to answer any questions you may have. You may obtain further information about your rights as a research subject by going to the 
Boston University Institutional Review Board website www.bu.edu/irb<http://www.bu.edu/irb> or calling Debora Perez, the IRB Coordinator of the Boston University Institutional Review Board, at (617) 358-6115. If any problems arise as a result of your participation in this study, including research-related injuries, please call the Principal Investigator, Dr. Stefan G. Hofmann, at (617) 353-9610 immediately.

\section{Consent}

I understand that my participation in the study is completely voluntary. Refusal to participate will involve no penalty or loss of benefits to which I would be otherwise entitled, and I may discontinue participation at any time without penalty or loss of benefits to which I may be otherwise entitled.

I have received a copy of this consent statement.

$\overline{\text { Signature of Person Obtaining Consent }}$

Date

Name of Participant (please print)

Date

Signature of Participant 


\title{
B/C PSYCHOTIC SCREENING MODULE (FOR SCID-I/NP OR P W/PSYCHOTIC SCREEN)
}

\author{
THIS MODULE IS FOR CODING PSYCHOTIC AND ASSOCIATED SXS THAT HAVE BEEN \\ PRESENT AT ANY POINT IN THE PERSON'S LIFETIME. IT CAN BE USED FOR CLINICAL AND \\ RESEARCH SETTINGS WHERE THOSE WITH A HISTORY OF PSYCHOTIC SXS THAT ARE NOT \\ DUE TO SUBSTANCE USE OR A GENERAL MEDICAL CONDITION OR THAT OCCUR OUTSIDE \\ THE CONTEXT OF A MOOD DISORDER ARE TO BE EXCLUDED.
}

\section{FOR EACH PSYCHOTIC SYMPTOM CODED "3," DESCRIBE THE ACTUAL CONTENT AND INDICATE THE PERIOD OF TIME DURING WHICH THE SYMPTOM WAS PRESENT. \\ FOR ANY PSYCHOTIC AND ASSOCIATED SYMPTOMS CODED "3," DETERMINE WHETHER THE SYMPTOM IS DEFINITELY "PRIMARY" OR WHETHER THERE IS A POSSIBLE OR DEFINITE ETIOLOGIC SUBSTANCE (INCLUDING MEDICATIONS) OR GENERAL MEDICAL CONDITION. THE FOLLOWING QUESTIONS MAY BE USEFUL IF THE OVERVIEW HAS NOT ALREADY PROVIDED THE INFORMATION:}

Just before (PSYCHOTIC SXS) began, were you using drugs? ...on any medications? ...did you drink much more than usual or stop drinking after you had been drinking a lot for a while? ...were you physically ill?

IF YES TO ANY: Has there been a time when you had (PSYCHOTIC SXS) and were not (USING DRUGS/TAKING MEDICATION/CHANGING YOUR DRINKING HABITS/ILL)?

Now I am going to ask you about unusual experiences that people sometimes have.

Has it ever seemed like people were talking about you or taking special notice of you?

IF YES: Were you convinced they were talking about you or did you think it might have been your imagination?

\section{DELUSIONS}

False personal beliefs based on incorrect inference about external reality and firmly sustained in spite of what almost everyone else believes and in spite of what constitutes incontrovertible and obvious proof or evidence to the contrary. The belief is not one ordinarily accepted by other members of the person's culture or subculture. Code overvalued ideas (unreasonable and sustained beliefs that are maintained with less than delusional intensity) as "2."

Delusion of reference, i.e., events, objects, or other people in the individual's immediate environment have a particular or unusual significance.

\section{DESCRIBE:}

\begin{tabular}{|c|c|}
\hline 1 & 3 \\
\hline 1 & 3 \\
\hline $\begin{array}{l}\text { POSS/DEF } \\
\text { SUBST/ } \\
\text { GMC }\end{array}$ & $\begin{array}{c}\text { PRI- } \\
\text { MARY }\end{array}$ \\
\hline
\end{tabular}

What about receiving special messages from the TV, radio, or newspaper, or from the way things were arranged around you? 
What about anyone going out of their way to give you a hard time, or trying to hurt you?

Have you ever felt that you were especially important in some way, or that you had special powers to do things that other people couldn't do?

Have you ever felt that something was very wrong with you physically even though your doctor said nothing was wrong...like you had cancer or some other terrible disease?

Have you ever been convinced that something was very wrong with the way a part or parts of your body looked?

Have you ever felt that something strange was happening to parts of your body?

Have you ever had any unusual religious experiences?

Have you ever felt that you had committed a crime or done something terrible for which you should be punished?

Were you ever convinced that your spouse or partner was being unfaithful to you?

IF YES: How did you know they were being unfaithful?

Did you ever feel you had a special, secret relationship with someone famous, or someone you didn't know very well?

Persecutory delusion, i.e., the individual (or his or her group) is being attacked, harassed, cheated, persecuted, or conspired against.

\section{DESCRIBE:}

Grandiose delusion, i.e., content involves exaggerated power, knowledge or importance, or a special relationship to a deity or famous person.

\section{DESCRIBE:}

Somatic delusion, i.e., content involves change or disturbance in body appearance or functioning.

\section{DESCRIBE:}
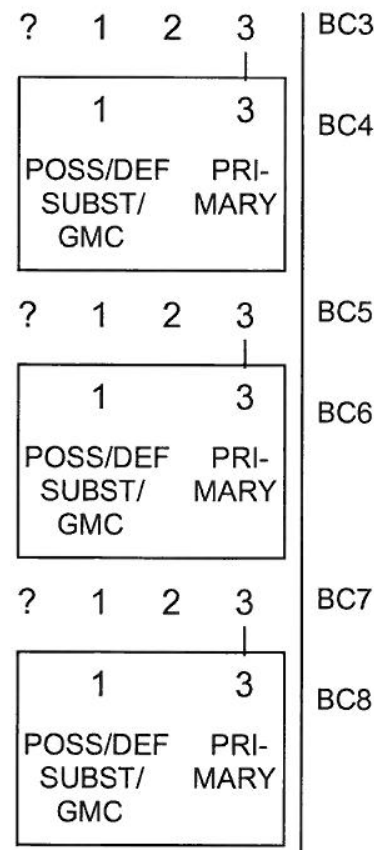

Other delusions

Check if: religious delusions

_ delusions of guilt jealous delusions erotomanic delusions

DESCRIBE:

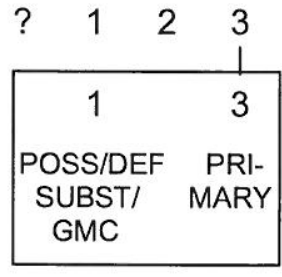

BC9 BC10 $\mathrm{BC} 11$ $\mathrm{BC} 12$ $\mathrm{BC} 13$ $\mathrm{BC} 14$ 
HALLUCINATIONS (PSYCHOTIC) A sensory perception that has the compelling sense of reality of a true perception but occurs without external stimulation of the relevant sensory organ. (CODE "2" FOR HALLUCINATIONS THAT ARE SO TRANSIENT AS TO BE WITHOUT DIAGNOSTIC SIGNIFICANCE)

Did you ever hear things that other people couldn't hear, such as noises, or the voices of people whispering or talking? (Were you awake at the time?)

IF YES: What did you hear? How often did you hear it?

IF VOICES: Did they comment on what you were doing or thinking?

How many voices did you hear? Were they talking to each other?

Did you ever have visions or see things that other people couldn't see? (Were you awake at the time?)
Auditory hallucinations when fully awake, heard either inside or outside of head

DESCRIBE:

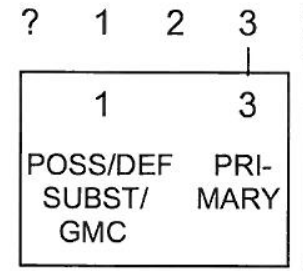

BC15

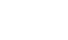

A voice keeping up a running commentary on the individual's behavior or thoughts as they occur

Two or more voices conversing with each other

Visual hallucinations

DESCRIBE:

\begin{tabular}{cccc}
$?$ & 1 & 2 & 3 \\
$?$ & 1 & 2 & 3 \\
\hline & 1 & 3 \\
$\begin{array}{c}\text { POSS/DEF } \\
\text { SUBST/ } \\
\text { GMC }\end{array}$ & $\begin{array}{c}\text { PRI- } \\
\text { MARY }\end{array}$ \\
\hline
\end{tabular}

NOTE: DISTINGUISH FROM AN

ILLUSION, I.E., A MISPERCEPTION OF

A REAL EXTERNAL STIMULUS. 
What about strange sensations in your body or on your skin?

(What about smelling or tasting things that other people couldn't smell or taste?)

IF A MAJOR DEPRESSIVE OR MANIC EPISODE HAS EVER BEEN PRESENT: Has there ever been a time when you had (PSYCHOTIC SXS) and you were not (DEPRESSED/MANIC)?
Tactile hallucinations, e.g., electricity

DESCRIBE:
Psychotic symptoms occur at times other than during mood syndromes

NOTE: CODE "3" IF NO MOOD SYNDROMES OR PSYCHOTIC SXS WIO MOOD EPISODES. CODE "1" ONLY IF PSYCHOTIC SYMPTOMS OCCUR EXCLUSIVELY DURING UNEQUIVOCAL MOOD SYNDROMES.

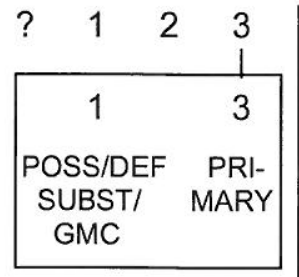

$\begin{array}{llll}? & 1 & 2 & 3\end{array}$ $\mathrm{BC} 23$

\begin{tabular}{|cc|}
\hline 1 & 3 \\
POSS/DEF & PRI- \\
SUBST/ & MARY \\
GMC & \\
\hline
\end{tabular}
BC24 $\mathrm{BC} 25$ BC26

DESCRIBE:

ANY ITEM CODED "3" IN "PRIMARY"

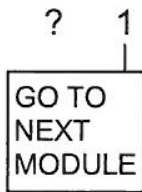
\begin{tabular}{|l|l|}
\multicolumn{1}{c|}{} & 3 \\
\hline A PRI- \\
MARY \\
PSYCHO- \\
TIC SX \\
HAS \\
BEEN \\
PRESENT
\end{tabular} BC27

\begin{tabular}{|l|}
\multicolumn{1}{|c}{} \\
\hline PSYCHO- \\
TIC MOOD \\
DISOR- \\
DER. \\
GO TO \\
NEXT \\
MODULE \\
\hline
\end{tabular}
BC28

EXPLORE DETAILS AND DESCRIBE DIAGNOSTIC SIGNIFICANCE: 


\section{E. SUBSTANCE USE DISORDERS}

\section{ALCOHOL USE DISORDERS (LIFETIME)}

IF SCREENING QUESTION \#1 ANSWERED "NO," CHECK HERE AND SKIP TO *NON-ALCOHOL SUBSTANCE USE DISORDERS, ${ }^{*}$ E. 9.

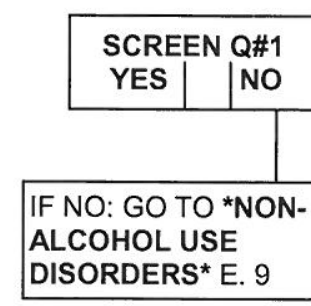

IF SCREENER NOT USED, OR IF QUESTION \#1 IS ANSWERED "YES," CONTINUE:

What are your drinking habits like? (How much do you drink?) (Has there ever been a time in your life when you had five or more drinks on one occasion?)

When in your life were you drinking the most? (How long did that period last?)

During that time...

how often were you drinking?

what were you drinking? how much?

During that time...

did your drinking cause problems for you?

did anyone object to your drinking?

IF ALCOHOL DEPENDENCE SEEMS LIKELY, CHECK HERE __ AND SKIP TO *ALCOHOL DEPENDENCE, ${ }^{*}$. 4.

IF ANY INCIDENTS OF EXCESSIVE DRINKING OR ANY EVIDENCE OF ALCOHOL-RELATED PROBLEMS, CONTINUE WITH *ALCOHOL ABUSE, * ON NEXT PAGE.

IF NEVER HAD ANY INCIDENTS OF EXCESSIVE DRINKING AND THERE IS NO EVIDENCE OF ANY ALCOHOL-RELATED PROBLEMS, SKIP TO *NON-ALCOHOL SUBSTANCE USE DISORDERS, ${ }^{*}$ E. 9. 


\section{*NON-ALCOHOL SUBSTANCE USE DISORDERS* (LIFETIME DEPENDENCE AND ABUSE)}

IF SCREENING QUESTIONS \#2 AND \#3 ARE BOTH ANSWERED "NO," CHECK HERE AND SKIP TO THE NEXT MODULE.

IF SCREENER NOT USED OR IF QUESTION \#2 OR QUESTION \#3 WAS ANSWERED "YES," CONTINUE:

Now I am going to ask you about your use of drugs or medicines.

\section{SHOW DRUG LIST TO SUBJECT.}

Have you ever taken any of these to get high, to sleep better, to lose weight, or to change your mood?

\section{CIRCLE THE NAME OF EACH DRUG EVER USED (OR WRITE IN NAME IF "OTHER")}

Sedatives-hypnotics-anxiolytics: Methaqualone (Quaalude, "ludes"), barbiturates, secobarbital (Seconal, "reds," "seccies," "dolls"), butalbital (Fiorinal), ethchlorvynol (Placidyl, "jelly-bellies"), meprobamate (Miltown, Equanil, "happy pills"), diazepam (Valium), alprazolam (Xanax), clonazepam (Klonopin), flunitrazepam (Rohypnol, "roofies"), temazepam (Restoril), flurazepam (Dalmane), chlordiazepoxide (Librium), lorazepam (Ativan), triazolam (Halcion), Ambien, Sonata, Lunesta, or other:

Cannabis: Marijuana ("pot", "grass", "weed", "reefer"), hashish ("hash"), THC

Stimulants: Amphetamine (Benzedrine, Adderall, "bennies," "black beauties"), "speed", metamphetamine ("crystal meth," "crank," "ice") dextroamphetamine (Dexedrine, "greenies"), methylphenidate (Ritalin, Concerta, Metadate, Focolin, "Vitamin R"), prescription diet pills or other:

Opioids: Heroin ("smack"), morphine, opium, methadone (Dolophine), dextropropoxyphene (Darvocet, Darvon), codeine, oxycodone (Percodan, Percoset, Oxycontin), hydrocodone (Vicodin, Lorcet), fentanyl (Duragesic, "percopop"), meperidine (Demerol), hydromorphone (Dilaudid) or other:

Cocaine: Snorting, IV, freebase, crack, "speedball," unspecified or other:

Hallucinogens/PCP: LSD ("acid"), mescaline, peyote, psilocybin (mushrooms), MDMA ("STP," "Ecstasy"), PCP ("angel dust", "peace pill"), ketamine ("Special K," "Vitamin K"), or other:

Other: Steroids, solvents (paint thinners, gasoline, glues, toluene), gases (butane, propane, aerosal propellants, nitrous oxide (laughing gas, "whippets"), nitrites (amyl nitrite, butyl nitrite, "poppers,"

"snappers"), DXM (DM, "Robo"), over-the-counter sleep or diet pills, ephedra, atropine, scopolamine or other:

?=inadequate information

$1=$ absent or false

\section{RECORD PERIOD OF HEAVIEST USE (AGE OR DATE, AND DURATION) AND DESCRIBE PATTERN OF USE}

IF NO TO BOTH: GO TO NEXT MODULE
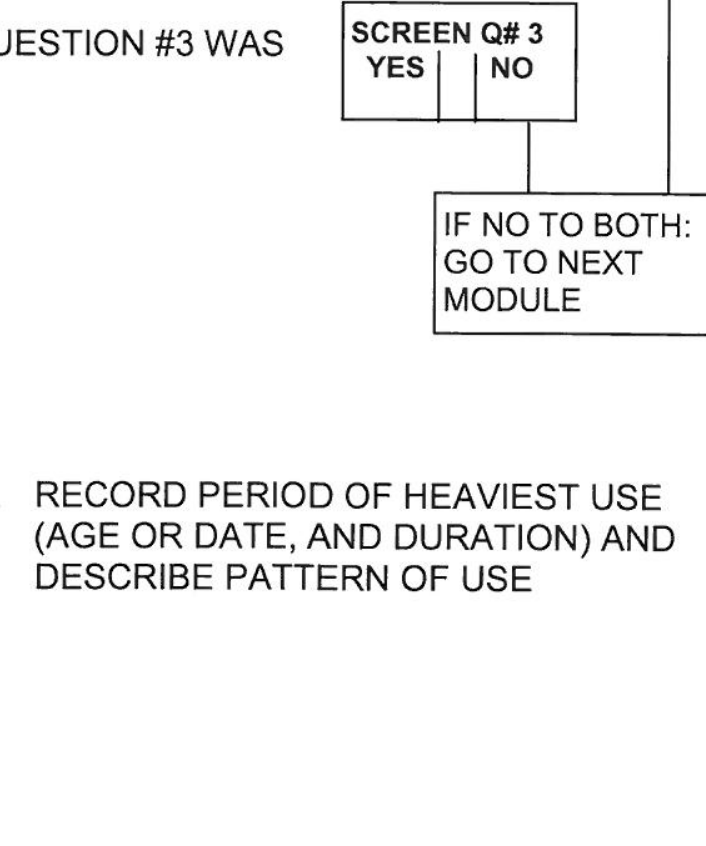
SCID-I (for DSM-IV-TR) Non-Alcohol Use Disorders (JAN 2007) Substance Use Disorders E. 10

IF SUBJECT HAS NOT USED ANY DRUG FROM ANY CLASS MORE THAN ONCE, CHECK HERE AND GO TO NEXT MODULE.

IF MORE THAN ONE DRUG USED (MORE THAN ONCE) DURING LIFETIME:

Which drug caused you the most problems?

IF SUBJECT DENIES PROBLEMS:

Which one did you use the most?

*INDICATE DRUG CLASS TO BE ASSESSED FOR DEPENDENCEIABUSE CRITERIA*

INDICATE DRUG CLASS TO BE ASSESSED FOR SUBSTANCE DEPENDENCE OR ABUSE. RETURN HERE, IF NECESSARY, AND RECODE DRUG CLASS IF THERE IS THE NEED TO ASSESS DEPENDENCE OR ABUSE FOR A DIFFERENT CLASS OF SUBSTANCE (E.G., CRITERIA NOT MET FOR DEPENDENCE OR ABUSE FOR FIRST DRUG CLASS, BUT THERE IS ALSO EVIDENCE OF HEAVY USE OF ANOTHER CLASS OF DRUG.)

$\begin{array}{cccccccc}\text { SED/ } & & & & & & & \\ \text { HYPN/ } & \text { CANN } & \text { STIMU } & \text { OPI } & \text { COC } & \text { HALL/ } & & \\ \text { ANX } & \text { ABIS } & \text { LANTS } & \text { OID } & \text { AINE } & \text { PCP } & \text { POLY } & \text { OTHER } \\ 3 & 3 & 3 & 3 & 3 & 3 & 3 & 3 \\ 1 & 1 & 1 & 1 & 1 & 1 & 1 & 1 \\ \text { E29 } & \text { E30 } & \text { E31 } & \text { E32 } & \text { E33 } & \text { E34 } & \text { E35 } & \text { E36 }\end{array}$

IF SUBSTANCE DEPENDENCE SEEMS LIKELY, CHECK HERE _ AND SKIP TO *SUBSTANCE DEPENDENCE, ${ }^{*}$ E. 13. 
Please answer the following questions (all information is kept strictly confidential).

How old are you?

What is your ethnic background? $\square \quad \square$ Hispanic / Latino

$\square \quad$ White

$\square \quad$ Black or African American

$\square \quad$ Native Hawaiian or other Pacific Islander

$\square \quad$ Native American / Alaska native

$\square$ Other:

What is your marital status?

Single

Living with partner

Married

Divorced

Widowed

Separated

What is your highest educational level?

$\square \quad$ Postgraduate

$\square \quad$ College Graduate

$\square \quad$ Partial College

$\square \quad$ High School Graduate

$\square \quad$ Partial High School

$\square \quad$ Junior High School

$\square \quad$ Less than 7 years of school

What is/was your highest occupational level?

$\square \quad$ Executive

$\square \quad$ Manager/Professional

$\square \quad$ Administrative

$\square \quad$ Clerical

$\square \quad$ Skilled

$\square \quad$ Semi-skilled

$\square \quad$ Unskilled 
Code:

Date:

What is your current living situation?

Urban

$\square \quad$ Suburban

$\square \quad$ Rural

What is your current income level?
$\square \quad 0-\$ 4,999$
$\square \quad \$ 5,000-\$ 9,999$
$\square \quad \$ 10,000-\$ 14,999$
$\square \quad \$ 15,000-\$ 24,999$
$\square \quad \$ 25,000-\$ 34,999$
$\square \quad \$ 35,000-\$ 49,999$
$\square \quad \$ 50,000-\$ 74,999$
$\square \quad \$ 75,000$ and higher

What is your present occupational status?
$\square \quad$ Full-time employment
$\square \quad$ Part-time employment
$\square \quad$ Unemployed
$\square \quad$ Student

What is your height? (feet and inches)

What is your weight? (pounds)

At what date did your last menstrual cycle start?

Do you currently use hormonal contraceptives (birth control pill)?

Please list the type and amount of medications that you are currently using: 
This questionnaire consists of 21 groups of statements. Please read each group of statements carefully, and then pick out the one statement in each group that best describes the way you have been feeling during the past two weeks, including today. Circle the number beside the statement you have picked. If several statements in the group seem to apply equally well, circle the highest number for that group. Be sure that you do not choose more than one statement for any group, including Item 16 (Changes in Sleeping Pattern) or Item 18 (Changes in Appetite).

\section{Sadness}

0

2

3

\section{Pessimism}

$0 \quad$ I am not discouraged about my future.

1 I feel more discouraged about my future than I used to be.

2 I do not expect things to work out for me.

3 I feel my future is hopeless and will only get worse.

\section{Past Failure}

$0 \quad$ I do not feel like a failure.

1 I have failed more than I should have.

2 As I look back, I see a lot of failures.

3 I feel I am a total failure as a person.

\section{Loss of Pleasure}

$0 \quad$ I get as much pleasure as I ever did from the things I enjoy.

1 I don't enjoy things as much as I used to.

$2 \quad$ I get very little pleasure from the things I used to enjoy.

3 I can't get any pleasure from things I used to enjoy.

\section{Guilty Feelings}

$0 \quad$ I don't feel particularly guilty.

1 I feel guilty over many things I have done or should have done.

2 I feel guilty most of the time.

3 I feel guilty all of the time.

\section{Punishment Feelings}

0 I don't feel I am being punished.

1 I feel I may be punished.

2 I expect to be punished.

3 I feel I am being punished.

\section{Self-Dislike}

0 I feel the same about myself as ever.

1 I have lost confidence in myself.

2 I am disappointed in myself.

3 I dislike myself.

\section{Self-Criticalness}

$0 \quad$ I don't criticize or blame myself more than usual.

1 I am more critical of myself than I used to be.

2 I criticize myself for all of my faults.

3 I blame myself for everything bad that happens.

\section{Suicidal Thoughts or Wishes}

$0 \quad$ I don't have any thoughts of killing myself.

1 I have thoughts of killing myself, but I would not carry them out.

2 I would like to kill myself.

3 I would like to kill myself if I had the chance.

10. Crying

$0 \quad$ I don't cry anymore than I used to.

I cry more than I used to. I cry over every little thing. I feel like crying, but I can't.

\section{Agitation}

$0 \quad$ I am no more restless our wound up than usual.

1 I feel more restless or wound up than usual.

2 I am so restless or agitated that it's hard to stay still.

3 I am so restless or agitated that I have to keep moving or doing something. 


\section{Loss of Interest}

$0 \quad$ I have not lost interest in other people or activities.

1 I am less interested in other people or things.

2 I have lost most of my interest in other people or things.

3 It's hard to get interested in anything.

\section{Indecisiveness}

$0 \quad$ I make decisions about as well as ever.

1 I find it more difficult to make decisions than usual.

2 I have much greater difficulty in making decisions than I used to.

3 I have trouble making any decisions.

\section{Worthlessness}

$0 \quad$ I do not feel worthless.

1 I don't consider myself as worthwhile and useful as I used to.

2 I feel more worthless as compared to other people.

3 I feel utterly worthless.

\section{Loss of Energy}

$0 \quad$ I have as much energy as ever.

1 I have less energy than I used to have.

2 I don't have enough energy to do very much.

3 I don't have enough energy to do anything.

\section{Changes in Sleeping Pattern}

$0 \quad$ I have not experienced any change in my sleeping pattern.

1a I sleep somewhat more than usual.

1b I sleep somewhat less than usual.

2a I sleep a lot more than usual.

$2 \mathrm{~b} \quad$ I sleep a lot less than usual.

3a I sleep most of the day.

3b I wake up 1-2 hours early and can't get back to sleep.

\section{Irritability}

$0 \quad$ I am no more irritable than usual.

1 I am more irritable than usual.

2 I am much more irritable than usual.

3 I am irritable all the time.

\section{Changes in Appetite}

$0 \quad$ I have not experienced any change in my appetite.

1a My appetite is somewhat less than usual.

1b My appetite is somewhat greater than usual.

2a My appetite is much less than before.

2b My appetite is much greater than usual.

3a I have no appetite at all.

$3 b \quad$ I crave food all the time.

\section{Concentration Difficulty}

$0 \quad$ I can concentrate as well as ever.

1 I can't concentrate as well as usual.

2 It's hard to keep my mind on anything for very long.

3 I find I can't concentrate on anything.

\section{Tiredness or Fatigue}

$0 \quad$ I am no more tired or fatigued than usual.

1 I get more tired or fatigued more easily than usual.

2 I am too tired or fatigued to do a lot of the things I used to do.

3 I am too tired or fatigued to do most of the things I used to do.

\section{Loss if Interest in Sex}

$0 \quad$ I have not noticed any recent change in my interest in sex.

1 I am less interested in sex than I used to be.

2 I am much less interested in sex now.

3 I have lost interest in sex completely. 


\section{STAI}

A number of statements which people have used to describe themselves are given below. Read each statement and then circle the appropriate number to the right of the statement to indicate how you generally feel. Please use the following scale:

\section{$1=$ almost never $; 2$ = sometimes; 3 = often; 4 = almost always.}

There are no right or wrong answers. Do not spend too much time on any one statement but give the answer which seems to describe how you generally feel.

\begin{tabular}{c|l|l}
1. & I feel pleasant & $1-2-3-4$ \\
\hline 2. & I tire quickly & $1-2-3-4$ \\
\hline 3. & I feel like crying & $1-2-3-4$ \\
\hline 4. & I wish I could be as happy as others seem to be & $1-2-3-4$ \\
\hline 5. & I am losing out on things because I can't make up my mind soon enough & $1-2-3-4$ \\
\hline 6. & I feel rested & $1-2-3-4$ \\
\hline 7. & I am “calm, cool, and collected" & $1-2-3-4$ \\
\hline 8. & I feel that difficulties are piling up so that I cannot overcome them & $1-2-3-4$ \\
\hline 9. & I worry too much over something that really doesn't matter & $1-2-3-4$ \\
\hline 10. & I am happy & $1-2-3-4$ \\
\hline 11. & I am inclined to take things hard & $1-2-3-4$ \\
\hline 12. & I lack self-confidence & $1-2-3-4$ \\
\hline 13. & I feel secure & $1-2-3-4$ \\
\hline 14. & I try to avoid facing a crisis or difficulty & $1-2-3-4$ \\
\hline 15. & I feel blue & $1-2-3-4$ \\
\hline 16. & I am content & $1-2-3-4$ \\
\hline 17. & Some unimportant thought runs through my mind and bothers me & \\
\hline 18. & I take disappointments so keenly that I can't put them out of my mind & $1-3-4$ \\
\hline 19. & I am a steady person & \begin{tabular}{l} 
\\
\hline 20.
\end{tabular} \\
interests & \\
\hline
\end{tabular}


Instructions: For each item, please circle the number to indicate the degree to which you feel the statement is characteristic or true for you. The rating scale is as follows:

$$
\begin{aligned}
& 0=\text { Not at all characteristic or true of me. } \\
& 1=\text { Slightly characteristic or true of me. } \\
& 2=\text { Moderately characteristic or true of me. } \\
& 3=\text { Very characteristic or true of me. } \\
& 4=\text { Extremely characteristic or true of me. }
\end{aligned}
$$

\begin{tabular}{|c|c|c|c|c|c|}
\hline CHARACTERISTIC & $\begin{array}{c}\text { NOT } \\
\text { AT ALL }\end{array}$ & SLIGHTLY & MODERATELY & VERY & EXTREMELY \\
\hline $\begin{array}{l}\text { 1. I get nervous if I have to speak with someone in } \\
\text { authority (teacher, boss, etc.). }\end{array}$ & 0 & 1 & 2 & 3 & 4 \\
\hline 2. I have difficulty making eye contact with others. & 0 & 1 & 2 & 3 & 4 \\
\hline $\begin{array}{l}\text { 3. I become tense if I have to talk about myself or } \\
\text { my feelings. }\end{array}$ & 0 & 1 & 2 & 3 & 4 \\
\hline $\begin{array}{l}\text { 4. I find it difficult to mix comfortably with the } \\
\text { people I work with. }\end{array}$ & 0 & 1 & 2 & 3 & 4 \\
\hline 5. I find it easy to make friends my own age. & 0 & 1 & 2 & 3 & 4 \\
\hline 6. I tense up if I meet an acquaintance in the street. & 0 & 1 & 2 & 3 & 4 \\
\hline 7. When mixing socially, I am uncomfortable. & 0 & 1 & 2 & 3 & 4 \\
\hline 8. I feel tense if I am alone with just one other person. & 0 & 1 & 2 & 3 & 4 \\
\hline 9. I am at ease meeting people at parties, etc. & 0 & 1 & 2 & 3 & 4 \\
\hline 10. I have difficulty talking with other people. & 0 & 1 & 2 & 3 & 4 \\
\hline 11. I find it easy to think of things to talk about. & 0 & 1 & 2 & 3 & 4 \\
\hline $\begin{array}{l}\text { 12. I worry about expressing myself in case I appear } \\
\text { awkward. }\end{array}$ & 0 & 1 & 2 & 3 & 4 \\
\hline $\begin{array}{l}\text { 13. I find it difficult to disagree with another's point } \\
\text { of view. }\end{array}$ & 0 & 1 & 2 & 3 & 4 \\
\hline $\begin{array}{l}\text { 14. I have difficulty talking to attractive persons of } \\
\text { the opposite sex. }\end{array}$ & 0 & 1 & 2 & 3 & 4 \\
\hline $\begin{array}{l}\text { 15. I find myself worrying that I won't know what to } \\
\text { say in social situations. }\end{array}$ & 0 & 1 & 2 & 3 & 4 \\
\hline 16. I am nervous mixing with people I don't know well. & 0 & 1 & 2 & 3 & 4 \\
\hline 17. I feel I'll say something embarrassing when talking. & 0 & 1 & 2 & 3 & 4 \\
\hline $\begin{array}{l}\text { 18. When mixing in a group, I find myself worrying I } \\
\text { will be ignored. }\end{array}$ & 0 & 1 & 2 & 3 & 4 \\
\hline 19. I am tense mixing in a group. & 0 & 1 & 2 & 3 & 4 \\
\hline $\begin{array}{l}\text { 20. I am unsure whether to greet someone I know } \\
\text { only slightly. }\end{array}$ & 0 & 1 & 2 & 3 & 4 \\
\hline
\end{tabular}




\section{SPAI}

\section{Developed by S. M. Turner, C. V. Dancu, and D. C. Beidel}

Below is a list of behaviors that may or may not be relevant for you. Based on your personal experience, please indicate how frequently you experience these feelings and thoughts in social situations. A social situation is defined as gathering of two or more people. For example: A meeting; a lecture; a party; bar or restaurant; conversing with one other person or group of people, etc. FEELING ANXIOUS IS A MEASURE OF HOW TENSE, NERVOUS OR UNBOMFORTABLE YOU ARE DURING SOCIAL ENCOUNTERS. Please use the scaled list below and circle the number which best reflects how frequently you experience these responses.

\begin{tabular}{|c|c|c|c|c|c|c|}
\hline $\begin{array}{c}\text { Never } \\
1\end{array}$ & $\begin{array}{c}\text { Very } \\
\text { infrequent } \\
2\end{array}$ & $\begin{array}{c}\text { Infrequent } \\
3\end{array}$ & $\begin{array}{c}\text { Sometimes } \\
4\end{array}$ & $\begin{array}{c}\text { Frequent } \\
5\end{array}$ & $\begin{array}{c}\text { Very } \\
\text { frequent } \\
6\end{array}$ & $\begin{array}{c}\text { Always } \\
7\end{array}$ \\
\hline
\end{tabular}

1. I feel anxious when entering social situations where there is a small group

2. I feel anxious when entering social situations where there is a large group....

3. I feel anxious when I am in an social situation and I become the center of attention.

4. I feel anxious when I am in a social situation and I am expected to engage in some activity.

5. I feel anxious when making a speech in front of an audience.

6. I feel anxious when speaking in a small informal meeting.

7. I feel so anxious about attending social gatherings that I avoid these situations.

$\begin{array}{lllllll}1 & 2 & 3 & 4 & 5 & 6 & 7\end{array}$

8. I feel so anxious in social situations that I leave the social gathering....

9. I feel anxious when in a small gathering with: strangers. authority figures. $\begin{array}{lllllll}1 & 2 & 3 & 4 & 5 & 6 & 7\end{array}$ opposite sex people in general.

10. I feel anxious when in a large gathering with: strangers.

$\begin{array}{lllllll}1 & 2 & 3 & 4 & 5 & 6 & 7 \\ 1 & 2 & 3 & 4 & 5 & 6 & 7 \\ 1 & 2 & 3 & 4 & 5 & 6 & 7 \\ 1 & 2 & 3 & 4 & 5 & 6 & 7\end{array}$

11. I feel anxious when in a bar or restaurant with: strangers.... 


\begin{tabular}{|c|c|c|c|c|c|c|}
\hline & Very & & & Very & \\
Never & infrequent & Infrequent & Sometimes & Frequent & frequent & Always \\
1 & 2 & 3 & 4 & 5 & 6 & 7 \\
\hline
\end{tabular}

12. I feel anxious and I do not know what to do when in a new situation with:

strangers.

authority figures

$\begin{array}{lllllll}1 & 2 & 3 & 4 & 5 & 6 & 7\end{array}$

opposite sex

$\begin{array}{lllllll}1 & 2 & 3 & 4 & 5 & 6 & 7\end{array}$

people in general

$\begin{array}{lllllll}1 & 2 & 3 & 4 & 5 & 6 & 7\end{array}$

$\begin{array}{lllllll}1 & 2 & 3 & 4 & 5 & 6 & 7\end{array}$

13. I feel anxious and I do not know what to do when in a situation involving confrontation with:

strangers.

authority figures.

$\begin{array}{lllllll}1 & 2 & 3 & 4 & 5 & 6 & 7\end{array}$

opposite sex

$\begin{array}{lllllll}1 & 2 & 3 & 4 & 5 & 6 & 7\end{array}$

people in general

$\begin{array}{lllllll}1 & 2 & 3 & 4 & 5 & 6 & 7\end{array}$

$\begin{array}{lllllll}1 & 2 & 3 & 4 & 5 & 6 & 7\end{array}$

14. I feel anxious and I do not know what to do when in an embarrassing situation with:

strangers.

authority figures.

opposite sex

people in general.

$\begin{array}{lllllll}1 & 2 & 3 & 4 & 5 & 6 & 7\end{array}$

$\begin{array}{lllllll}1 & 2 & 3 & 4 & 5 & 6 & 7\end{array}$

$\begin{array}{lllllll}1 & 2 & 3 & 4 & 5 & 6 & 7\end{array}$

$\begin{array}{lllllll}1 & 2 & 3 & 4 & 5 & 6 & 7\end{array}$

15. I feel anxious when discussing intimate feelings with:

strangers.

$\begin{array}{lllllll}1 & 2 & 3 & 4 & 5 & 6 & 7\end{array}$

authority figures.

opposite sex

people in general.

$\begin{array}{lllllll}1 & 2 & 3 & 4 & 5 & 6 & 7\end{array}$

$\begin{array}{lllllll}1 & 2 & 3 & 4 & 5 & 6 & 7\end{array}$

$\begin{array}{lllllll}1 & 2 & 3 & 4 & 5 & 6 & 7\end{array}$

16. I feel anxious when stating an opinion to:

strangers....

$\begin{array}{lllllll}1 & 2 & 3 & 4 & 5 & 6 & 7\end{array}$

authority figures......

$\begin{array}{lllllll}1 & 2 & 3 & 4 & 5 & 6 & 7\end{array}$

opposite sex.

people in general.

$\begin{array}{lllllll}1 & 2 & 3 & 4 & 5 & 6 & 7\end{array}$

$\begin{array}{lllllll}1 & 2 & 3 & 4 & 5 & 6 & 7\end{array}$

17. I feel anxious when talking about business with:

strangers

authority figures

$\begin{array}{lllllll}1 & 2 & 3 & 4 & 5 & 6 & 7\end{array}$

opposite sex

$\begin{array}{lllllll}1 & 2 & 3 & 4 & 5 & 6 & 7\end{array}$

people in general.

$\begin{array}{lllllll}1 & 2 & 3 & 4 & 5 & 6 & 7\end{array}$

$\begin{array}{lllllll}1 & 2 & 3 & 4 & 5 & 6 & 7\end{array}$

18. I feel anxious when approaching and/or initiating a conversation with: strangers.

authority figures.

opposite sex.....

$\begin{array}{lllllll}1 & 2 & 3 & 4 & 5 & 6 & 7\end{array}$

people in general.

$\begin{array}{lllllll}1 & 2 & 3 & 4 & 5 & 6 & 7\end{array}$

$\begin{array}{lllllll}1 & 2 & 3 & 4 & 5 & 6 & 7\end{array}$ 


\begin{tabular}{|c|c|c|c|c|c|c|}
\hline & Very & & & Very & \\
Never & infrequent & Infrequent & Sometimes & Frequent & frequent & Always \\
1 & 2 & 3 & 4 & 5 & 6 & 7 \\
\hline
\end{tabular}

19. I feel anxious when having to interact for longer than a few minutes with:

strangers.

authority figures

opposite sex.

people in general.

$\begin{array}{lllllll}1 & 2 & 3 & 4 & 5 & 6 & 7 \\ 1 & 2 & 3 & 4 & 5 & 6 & 7 \\ 1 & 2 & 3 & 4 & 5 & 6 & 7 \\ 1 & 2 & 3 & 4 & 5 & 6 & 7\end{array}$

20. I feel anxious when drinking (any type of beverage) and/or eating in front of:

strangers

authority figures

opposite sex

people in general.

$\begin{array}{lllllll}1 & 2 & 3 & 4 & 5 & 6 & 7 \\ 1 & 2 & 3 & 4 & 5 & 6 & 7 \\ 1 & 2 & 3 & 4 & 5 & 6 & 7 \\ 1 & 2 & 3 & 4 & 5 & 6 & 7\end{array}$

21. I feel anxious when writing or typing in front of:

strangers.

authority figures.

opposite sex

people in general.

$\begin{array}{lllllll}1 & 2 & 3 & 4 & 5 & 6 & 7 \\ 1 & 2 & 3 & 4 & 5 & 6 & 7 \\ 1 & 2 & 3 & 4 & 5 & 6 & 7 \\ 1 & 2 & 3 & 4 & 5 & 6 & 7\end{array}$

22. I feel anxious when speaking in front of:

strangers.

authority figures

$\begin{array}{lllllll}1 & 2 & 3 & 4 & 5 & 6 & 7\end{array}$

opposite sex

people in general.

$\begin{array}{lllllll}1 & 2 & 3 & 4 & 5 & 6 & 7\end{array}$

$\begin{array}{lllllll}1 & 2 & 3 & 4 & 5 & 6 & 7\end{array}$

$\begin{array}{lllllll}1 & 2 & 3 & 4 & 5 & 6 & 7\end{array}$

23. I feel anxious when being criticized or rejected by:

strangers.

authority figures.

opposite sex.

$\begin{array}{lllllll}1 & 2 & 3 & 4 & 5 & 6 & 7\end{array}$

$\begin{array}{lllllll}1 & 2 & 3 & 4 & 5 & 6 & 7\end{array}$

people in general.

$\begin{array}{lllllll}1 & 2 & 3 & 4 & 5 & 6 & 7\end{array}$

$\begin{array}{lllllll}1 & 2 & 3 & 4 & 5 & 6 & 7\end{array}$

24. I attempt to avoid social situations where there are:

strangers.

$\begin{array}{lllllll}1 & 2 & 3 & 4 & 5 & 6 & 7\end{array}$

authority figures....

opposite sex.

people in general.

$\begin{array}{lllllll}1 & 2 & 3 & 4 & 5 & 6 & 7\end{array}$

$\begin{array}{lllllll}1 & 2 & 3 & 4 & 5 & 6 & 7\end{array}$

$\begin{array}{lllllll}1 & 2 & 3 & 4 & 5 & 6 & 7\end{array}$

25. I leave social situations where there are:

strangers

authority figures.

opposite sex....

people in general.

$\begin{array}{lllllll}1 & 2 & 3 & 4 & 5 & 6 & 7\end{array}$

$\begin{array}{lllllll}1 & 2 & 3 & 4 & 5 & 6 & 7\end{array}$

$\begin{array}{lllllll}1 & 2 & 3 & 4 & 5 & 6 & 7\end{array}$

$\begin{array}{lllllll}1 & 2 & 3 & 4 & 5 & 6 & 7\end{array}$

26. Before entering a social situation I think about all the things that can go wrong. The types of thoughts I experience are:

Will I be dressed properly?

$\begin{array}{lllllll}1 & 2 & 3 & 4 & 5 & 6 & 7\end{array}$

I will probably make a mistake and look foolish.

$\begin{array}{lllllll}1 & 2 & 3 & 4 & 5 & 6 & 7\end{array}$

What will I do if no one speaks to me?

$\begin{array}{lllllll}1 & 2 & 3 & 4 & 5 & 6 & 7\end{array}$

If there is a lag in the conversation what can I talk about?

$\begin{array}{lllllll}1 & 2 & 3 & 4 & 5 & 6 & 7\end{array}$ 


\begin{tabular}{|c|c|c|c|c|c|c|}
\hline & Very & & & Very & \\
1 & infrequent & Infrequent & Sometimes & Frequent & frequent & Always \\
\hline
\end{tabular}

People will notice how anxious I am.

$\begin{array}{lllllll}1 & 2 & 3 & 4 & 5 & 6 & 7\end{array}$

27. I feel anxious before entering a social situation.

$\begin{array}{lllllll}1 & 2 & 3 & 4 & 5 & 6 & 7\end{array}$

28. My voice leaves me or changes when I am talking in a social situation.

29. I am not likely to speak to people until they speak to me

$\begin{array}{lllllll}1 & 2 & 3 & 4 & 5 & 6 & 7\end{array}$

30. I experience troublesome thoughts when I am in a social setting. For example:

I wish I could leave and avoid the whole situation.

$\begin{array}{lllllll}1 & 2 & 3 & 4 & 5 & 6 & 7\end{array}$

If I mess up again I will really lose my confidence.

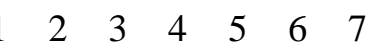

What kind of impression am I making?

$\begin{array}{lllllll}1 & 2 & 3 & 4 & 5 & 6 & 7\end{array}$

Whatever I say it will probably sound stupid.

$\begin{array}{lllllll}1 & 2 & 3 & 4 & 5 & 6 & 7\end{array}$

31. I experience the following prior to entering a social situation:

sweating

$\begin{array}{lllllll}1 & 2 & 3 & 4 & 5 & 6 & 7\end{array}$

frequent urge to urinate

$\begin{array}{lllllll}1 & 2 & 3 & 4 & 5 & 6 & 7\end{array}$

heart palpitations.

$\begin{array}{lllllll}1 & 2 & 3 & 4 & 5 & 6 & 7\end{array}$

32. I experience the following in a social situation:

sweating.

$\begin{array}{lllllll}1 & 2 & 3 & 4 & 5 & 6 & 7\end{array}$

blushing.

$\begin{array}{lllllll}1 & 2 & 3 & 4 & 5 & 6 & 7\end{array}$

shaking.

$\begin{array}{lllllll}1 & 2 & 3 & 4 & 5 & 6 & 7\end{array}$

frequent urge to urinate.

$\begin{array}{lllllll}1 & 2 & 3 & 4 & 5 & 6 & 7\end{array}$

heart palpitations.

$\begin{array}{lllllll}1 & 2 & 3 & 4 & 5 & 6 & 7\end{array}$

33. I feel anxious when I am home alone.

$\begin{array}{lllllll}1 & 2 & 3 & 4 & 5 & 6 & 7\end{array}$

34. I feel anxious when I am in a strange place.

$\begin{array}{lllllll}1 & 2 & 3 & 4 & 5 & 6 & 7\end{array}$

35. I feel anxious when I am on any form of public transportation (i.e., bus, train, airplane)

$\begin{array}{lllllll}1 & 2 & 3 & 4 & 5 & 6 & 7\end{array}$

36. I feel anxious when crossing streets.

$\begin{array}{lllllll}1 & 2 & 3 & 4 & 5 & 6 & 7\end{array}$

37. I feel anxious when I am in crowded public places (i.e., stores, church, movies, restaurants, etc.)

$\begin{array}{lllllll}1 & 2 & 3 & 4 & 5 & 6 & 7\end{array}$

38. Being in large open spaces makes me feel anxious.

$\begin{array}{lllllll}1 & 2 & 3 & 4 & 5 & 6 & 7\end{array}$

39. I feel anxious when I am in enclosed places (elevators, tunnels, etc.)....

40. Being in high places makes me feel anxious (i.e., tall buildings)......

$\begin{array}{lllllll}1 & 2 & 3 & 4 & 5 & 6 & 7\end{array}$

41. I feel anxious when waiting in a long line.

$\begin{array}{lllllll}1 & 2 & 3 & 4 & 5 & 6 & 7\end{array}$

$\begin{array}{lllllll}1 & 2 & 3 & 4 & 5 & 6 & 7\end{array}$

42. There are times when I feel like I have to hold on things because I am afraid I will fall.

43. When I leave home and go to various public places, I go with a family member or friend.

$\begin{array}{lllllll}1 & 2 & 3 & 4 & 5 & 6 & 7\end{array}$

44. I feel anxious when riding a car.

$\begin{array}{lllllll}1 & 2 & 3 & 4 & 5 & 6 & 7\end{array}$

45. There are certain places I do not go to because I may feel trapped....

$\begin{array}{lllllll}1 & 2 & 3 & 4 & 5 & 6 & 7\end{array}$ 


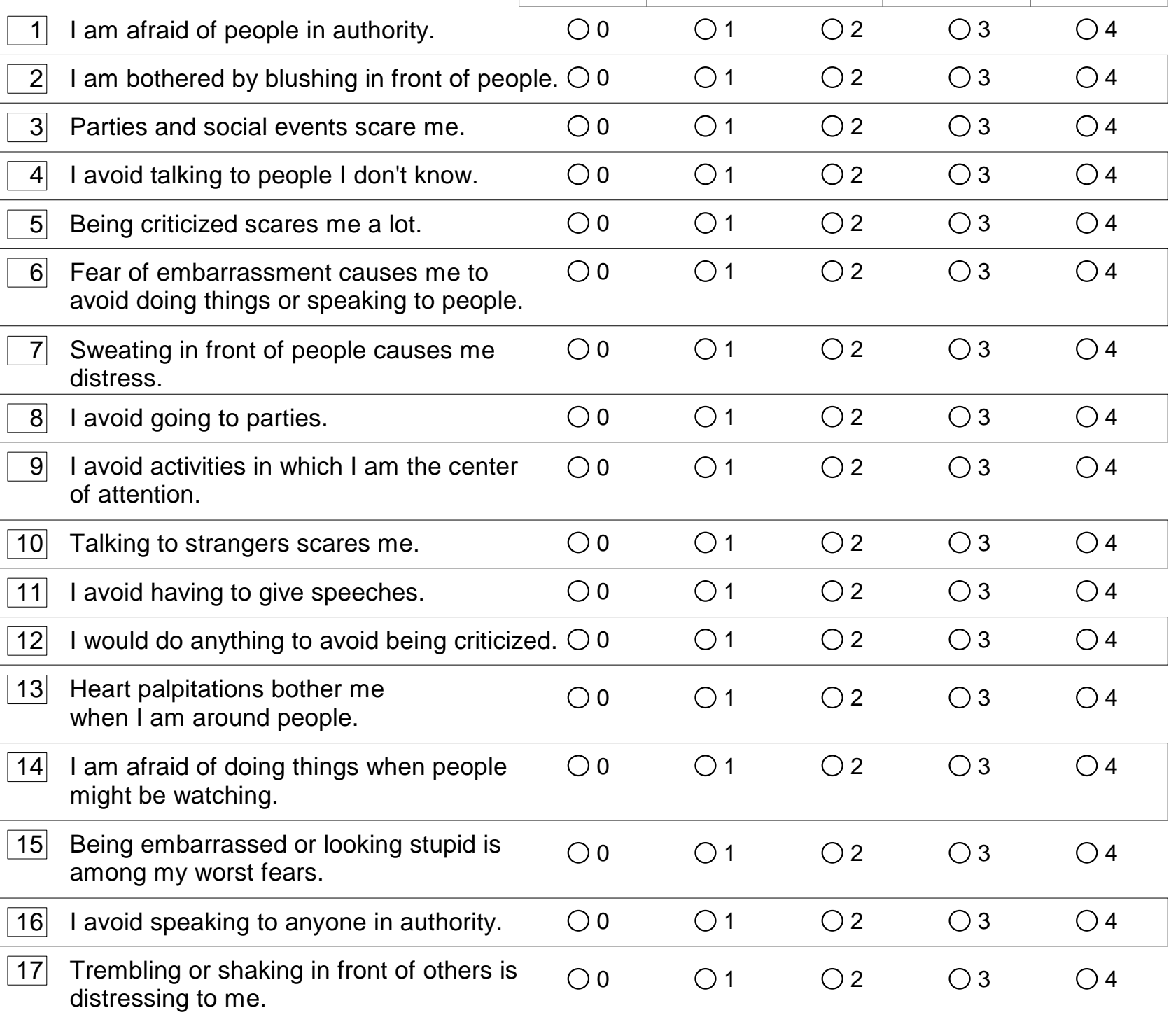

